\title{
Processing Afferent Proprioceptive Information at the Main Cuneate Nucleus of Anesthetized Cats
}

\author{
Roberto Leiras, Patricia Velo, Francisco Martín-Cora, and Antonio Canedo \\ Health Research Institute, Department of Physiology, Faculty of Medicine, University of Santiago de Compostela, 15704 Santiago de Compostela, Spain
}

Medial lemniscal activity decreases before and during movement, suggesting prethalamic modulation, but the underlying mechanisms are largely unknown. Here we studied the mechanisms underlying proprioceptive transmission at the midventral cuneate nucleus $(\mathrm{mvCN})$ of anesthetized cats using standard extracellular recordings combined with electrical stimulation and microiontophoresis. Dual simultaneous recordings from $\mathrm{mvCN}$ and rostroventral cuneate $(\mathrm{rvCN})$ proprioceptive neurons demonstrated that microstimulation through the rvCN recording electrode induced dual effects on $\mathrm{mvCN}$ projection cells: potentiation when both neurons had excitatory receptive fields in muscles acting at the same joint, and inhibition when rvCN and mvCN cells had receptive fields located in different joints. GABA and/or glycine consistently abolished mvCN spontaneous and sensory-evoked activity, an effect reversed by bicuculline and strychnine, respectively; and immunohistochemistry data revealed that cells possessing strychnine-sensitive glycine receptors were uniformly distributed throughout the cuneate nucleus. It was also found that proprioceptive mvCN projection cells sent ipsilateral collaterals to the nucleus reticularis gigantocellularis and the mesencephalic locomotor region, and had slower antidromic conduction speeds than cutaneous fibers from the more dorsally located cluster region.

The data suggest that (1) the rvCN-mvCM network is functionally related to joints rather than to single muscles producing an overall potentiation of proprioceptive feedback from a moving forelimb joint while inhibiting, through GABAergic and glycinergic interneurons, deep muscular feedback from other forelimb joints; and (2) $\mathrm{mvCN}$ projection cells collateralizing to or through the ipsilateral reticular formation allow for bilateral spreading of ascending proprioceptive feedback information.

\section{Introduction}

The central goal of this work is to study the mechanisms underlying ascending modulation and transmission of muscular proprioceptive feedback through the main cuneate nucleus.

Low-threshold mechanoreceptive fibers maintain a somatotopic arrangement up to the cuneatus and gracilis nuclei (Uddenberg, 1966; Whitsel et al., 1969), where they synapse onto submodality-specific neurons segregated rostrocaudally (Kruger et al., 1961; Perl et al., 1962; Gordon and Jukes, 1964; Rosén, 1969a; Carmody and Rowe, 1974; Millar and Basbaum, 1975; Bystrzycka et al., 1977; Douglas et al., 1978; Golovchinsky, 1980; Dykes et al., 1982; Hummelsheim et al., 1985; Berkley et al., 1986).

Proprioceptive information from the upper trunk and forelimbs follows parallel pathways to the external and main cuneate nuclei. In the main cuneate, the proprioceptive cells are mostly

Received April 28, 2010; revised Aug. 20, 2010; accepted Aug. 28, 2010.

This work and R.L. were supported by grants from the Spanish Ministerio de Ciencia y Tecnología (BFU200606598 and BFU2009-12803) and the Xunta de Galicia (09CSA010208PR). F.M.-C. was a postdoctoral fellow supported by the Ramón y Cajal program. P.V. was supported by the Spanish Formación de Personal Investigador program. The content of this paper is part of the doctoral thesis of R.L. to obtain a PhD at the Department of Physiology, University of Santiago de Compostela. We express our gratitude to Gonzalo Pichel from the University's technical service for building the system of limb fixation and angular displacement.

Correspondence should be addressed to Dr. Antonio Canedo, Department of Physiology, Faculty of Medicine, University of Santiago de Compostela, 15704 Santiago de Compostela, Spain. E-mail: antonio.canedo@usc.es.

DOI:10.1523/JNEUROSCI.2193-10.2010

Copyright $\odot 2010$ the authors $\quad 0270-6474 / 10 / 3015383-17 \$ 15.00 / 0$ located in the rostroventral ( $\mathrm{rvCN})$ and midventral $(\mathrm{mvCN})$ regions (Dykes et al., 1982; Nyberg and Blomqvist, 1982) and are segregated from cutaneous cells that are located more dorsally (Kuhn, 1949; Yamamoto et al., 1956; Perl et al., 1962; Gordon and Jukes, 1964; Pubols et al., 1965; Winter, 1965; Rosén, 1967, 1969a; Millar and Basbaum, 1975; Dykes et al., 1982). The cutaneous neurons rostral to the obex project mainly to the cerebellum (Cooke et al., 1971a; Cheek et al., 1975; Haring et al., 1984; Cerminara et al., 2003), forming the exteroceptive component of the cuneocerebellar tract, whereas the proprioceptive component of the same tract originates exclusively from the external cuneate nucleus (Cooke et al., 1971a,b; Cheek et al., 1975).

The great majority of the mvCN proprioceptive neurons project through the medial lemniscus (ML) (Rosén, 1969b; Rosén and Sjölund, 1973; Cheek et al., 1975; Ellis and Rustioni, 1981; Hummelsheim and Wiesendanger, 1985; Rowinski et al., 1985; Pubols et al., 1989; Mackie et al., 1998), whereas only a minor proportion of the rvCN proprioceptive cells do (Kuypers and Tuerk, 1964; Blum et al., 1975; Cheek et al., 1975). Transmission through the ML decreases before and during movement (Ghez and Lenzi, 1971; Ghez and Pisa, 1972; Coulter, 1974; Chapman et al., 1988), suggesting prethalamic modulation, but the underlying mechanisms influencing proprioceptive ascending transmission at the main cuneate nucleus are largely unknown.

The rvCN projects to structures implicated in sensory and motor integration, including the inferior olive (Berkley et al., 
1986; McCurdy et al., 1998), tectum (Hand and Van Winkle, 1977; Wiberg and Blomqvist, 1984; Berkley et al., 1986), red nucleus (Edwards, 1972; Berkley et al., 1986), and cochlear nuclei (Itoh et al., 1987; Weinberg and Rustioni, 1987; Wright and Ryugo, 1996). Accordingly, we hypothesized that the rvCN might also project to the mvCN to influence the activity of projection or cuneolemniscal (CL) cells sensitive to deep input from muscle proprioceptors. Testing this hypothesis was the main objective of this study.

A second aim was to examine the effects induced on mvCN projection neurons by electrically stimulating the nucleus reticularis gigantocellularis (NRGc) and the mesencephalic locomotor region (MLR), two structures anatomically interconnected, receiving polysensory input, and implicated in sensorimotor integration (Armstrong, 1988; Whelan, 1996; Canedo, 1997; Jordan, 1998; Takakusaki et al., 2003; Winn, 2008).

Preliminary data have been reported in abstract form (Leiras et al., 2009).

\section{Materials and Methods}

General. All procedures conformed to the International Council for Laboratory Animal Science and European Union Council Directive 86/609 EEC, and were approved by the University Animal Care Committee. Successful experiments were conducted on a total of 30 domestic male cats weighing between 3 and $4.5 \mathrm{~kg}$. Surgical anesthesia was induced with ketamine $\mathrm{HCl}(10-20 \mathrm{mg} / \mathrm{kg}$, i.m.) and continued with $\alpha$-chloralose (65 $\mathrm{mg} / \mathrm{kg}$, i.v.). Additional doses of anesthesia (1/2 of a full dose) were regularly administered every $4-5 \mathrm{~h}$. The depth of anesthesia was assessed by monitoring the heart rate and the electrocorticogram (ECoG; digitally filtered at a frequency passband of 1 to $50-100 \mathrm{~Hz}$ ), and by observing the state of the pupil. Changes of heart rate (maintained in the range of $90-120$ beats $/ \mathrm{min}$ ) or in the pattern of the ECoG (high-amplitude and low-frequency waves were taken as a sign of adequate anesthesia), and dilated pupils or pupils reacting rapidly to electrical stimuli were considered to reflect inadequate anesthesia, in which case a supplementary half dose of $\alpha$-chloralose was immediately injected. Rectal temperature was maintained between 37 and $38^{\circ} \mathrm{C}$ with a servo-controlled DC heating pad. Tracheal and venous cannulae were inserted, the animals were placed in a stereotaxic headholder, the dorsal caudal medulla was exposed, and a portion of the cerebellum was removed to allow access to the tissue rostral to the obex. The animals were fixed to the stereotaxic apparatus with thoracic and lumbar vertebral clamps. Lidocaine hydrochloride $(2 \%)$ was added to all insertion points. Before recording, the cats were ventilated artificially with the control of end-tidal $\mathrm{CO}_{2}$ at $4 \pm 0.3 \%$ by adjusting the respiratory rate and the inspired volume. After the ECoG showed typical signs of deep general anesthesia, a paralyzing dose of vecuronium bromide $(0.2-0.3 \mathrm{mg} / \mathrm{kg} / \mathrm{h}$, i.v. $)$ dissolved in a $\mathrm{pH}$-balanced solution of $5 \%$ glucose in physiological saline was continuously infused ( $4 \mathrm{ml} / \mathrm{h}$, i.v.) through a tail vein. A bilateral pneumothorax was routinely performed to minimize respiratory pulsations. Warm agar (2\% in physiological saline) was added to all exposed areas to increase stability and avoid desiccation. A concentric bipolar electrode (SNE-100X, Rhodes Medical Instruments) was lowered to a depth of 1-1.5 $\mathrm{mm}$ in the lateral tip of the cruciate sulcus to continuously monitor the electrocorticographic activity (digitally filtered at a frequency passband of $5-100 \mathrm{~Hz}$ ). A bipolar stimulating electrode (NE-100X, Rhodes Medical Instruments) was stereotaxically placed in the contralateral ML at Horsley-Clark coordinates A2, L4.5, $\mathrm{H}-5$, which served to identify CL cells according to standard criteria, including in all cases the collision test (see Figs. 2A1, $4 B, 5 A, B, 6 A 1,7 E, 8 A, 10 B)$.

Stimulation and recording procedures. In a first series of experiments ( 8 cats), single-unit recordings were obtained from cuneate proprioceptive cells located from $4 \mathrm{~mm}$ rostral to $4 \mathrm{~mm}$ caudal to the obex. Stimulating bipolar electrodes (SNEX-200X, Rhodes Medical Instruments) were visually placed contralaterally in the forelimb motor cortex and in the postcruciate dimple, and ipsilaterally in the NRGc (P6 to P8, 1-1.5 mm lateral to the midline, $3-5 \mathrm{~mm}$ deep from the floor of the fourth ventricle) and the mesencephalic locomotor region ( $\mathrm{P} 2, \mathrm{~L} 4, \mathrm{H}-1$ to -2$)$. These electrodes served to test whether cuneate proprioceptive neurons were differently affected by motor and/or somatosensory cortices, and by NRGc and/or MLR stimulation.

In a second series of experiments (18 cats), simultaneous paired recordings from cells activated by forelimb muscular proprioceptive input were obtained from the ventralmost region of the rostral (rvCN; $0.5-4$ $\mathrm{mm}$ anterior to the obex; $1-3.5 \mathrm{~mm}$ lateral) and medial (mvCN; $0-3.5$ $\mathrm{mm}$ posterior to the obex; $1-2.5 \mathrm{~mm}$ lateral) cuneate nucleus. This permitted us to compare the behavior of rvCN and mvCN cells with overlapping and non-overlapping excitatory proprioceptive fields. The midline and obex served as visible references on the dorsal surface of the brainstem. After mvCN cells activated by muscle stretch were recorded through both electrodes, the rostral one was intermittently switched to stimulation to pass cathodic pulses ( $0.05-0.5 \mathrm{~ms}$ pulse duration; $50-150$ $\mu \mathrm{A}$ current intensity) relative to an $\mathrm{Ag}-\mathrm{AgCl}$ reference anode implanted in a nearby muscle. This procedure permitted us to study the effects induced by microstimulating a region of the rvCN, where a particular proprioceptive field was observed, on proprioceptive cells simultaneously recorded in the mvCN showing overlapping and nonoverlapping proprioceptive fields. In these experiments, an additional stimulating bipolar electrode (NE-100X, Rhodes Medical Instruments) was placed in the ipsilateral inferior cerebellar peduncle (P8.5, L6, H-5) (Fig. 1), serving to discriminate whether the rostral recording/stimulating electrode was positioned in the external cuneate or in the rvCN nucleus (Cooke et al., 1971a; Mackie et al., 1999). None of the studied rvCN cells responded antidromically to stimulation of the inferior cerebellar peduncle.

In a first set of these animals $(n=10)$, the activity of single mvCN neurons was recorded with tungsten electrodes (6-12 M $\Omega$ impedance), and in a second set $(n=8)$, four- or six-barreled pipettes were used for extracellular recording and iontophoresis. Standard controls for $\mathrm{pH}$ and current balancing were performed (Roberts and Gould, 1993). The center barrel of each multipipette was filled with $3 \mathrm{M} \mathrm{NaCl}$ for recording, one barrel was used for current balancing, and each of the remaining barrels was filled with a solution of one of the following drugs: GABA ( $1 \mathrm{M}, \mathrm{pH}$ 4), bicuculline methiodide $\left(\mathrm{BiCu}, 20 \mathrm{~mm}, \mathrm{pH} 4: \mathrm{GABA}_{\mathrm{A}}\right.$ receptor antagonist), glycine ( $1 \mathrm{M}, \mathrm{pH} 3.5)$, or strychnine (10 mM, $\mathrm{pH} 6.5$; glycine receptor antagonist). Ejecting positive DC currents of 1-25 nA for GABA and glycine and of $10-75 \mathrm{nA}$ for $\mathrm{BiCu}$ and strychnine were used. The drugs were typically administered in 2-5 nA steps of increasing current while monitoring changes in spontaneous as well as in sensory-andelectrically evoked activity. The currents used for $\mathrm{BiCu}$ and strychnine were selected by measuring the current level required to reverse the effect of iontophoresed GABA and glycine, respectively. When not in use, each drug barrel was subjected to a $10-20 \mathrm{nA}$ negative retaining current to prevent unwanted diffusion from the pipette.

The effects produced by electrical stimulation were averaged for $30-$ 100 trials in control conditions, again during ejection of drugs, and finally after recovery. Stability was ascertained by comparing responses collected during the first and the last set of trials, and only cells that showed recovery of responses to at least $75 \%$ of control were included in the study. Peristimulus and poststimulus histograms were constructed from the accumulated number of all spikes in the response for the total number of sweeps. Neuronal injury discharges and presumed fiber recordings (positive discharges of $\leq 0.5 \mathrm{~ms}$ duration) were disregarded. The mean measures in the control versus in the presence of drugs as well as the average conduction velocities were compared by using parametric ( $t$ test) or nonparametric (Mann-Whitney $U$ test) tests as appropriated.

Criteria to sample proprioceptive cuneate neurons. For each unit recorded, localization of the receptive field was initially made qualitatively by searching the skin, limb joints, and muscles for input to the recorded unit. The proprioceptive neurons sensitive to manual stretch were assumed to be associated with proprioceptors whose approximate locations were then identified by mechanical tapping and probing the muscle by using a metal or glass probe (1-1.5 $\mathrm{mm}$ diameter). Once the approximate receptor's location was established, a feedback-controlled mechanical stimulator was used to apply controlled mechanical stimuli to the focus of maximum sensitivity at $130-135 \mathrm{~Hz}$ and different strengths. 


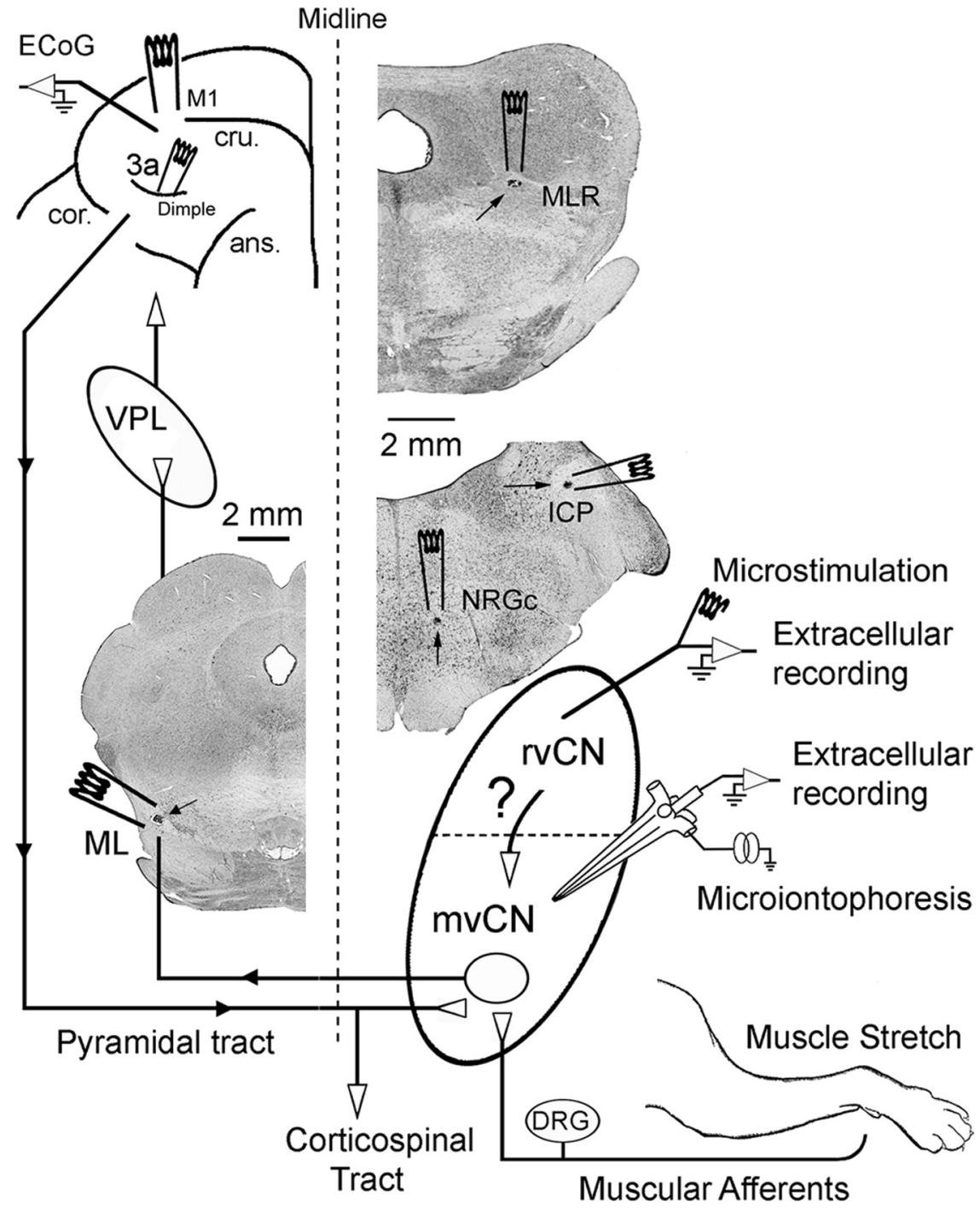

Figure 1. General experimental arrangement. Stimulating electrodes were placed in the contralateral ML, the primary motor cortex (M1), and area 3a; and in the ipsilateral NRGc, inferior cerebellar peduncle (ICP), and MLR. Extracellular simultaneous recording was performed at the rvCN and mvCN. Microstimulation applied through the rvCN recording electrode served to test its effects on mvCN proprioceptive cells. Microiontophoretic ejection was used to test the effects exerted by GABA and glycine on the spontaneous and evoked activity of mvCN neurons. See text for further details. Three coronal sections show small electrolytic lesions (signaled by arrows) at the ML, MLR, NRGc, and ICP. ans, Ansate sulcus; cru, cruciate sulcus; cor, coronal sulcus; DRG, dorsal root ganglia; VPL, thalamic ventroposterolateral nucleus.

Neurons were considered to respond to activated muscle proprioceptors when they (1) were sensitive to sinusoidal muscle stretching (Lundberg and Winsbury, 1960; Bianconi and van der Meulen, 1963; Brown et al., 1967; Matthews and Stein, 1969; Stuart et al., 1970; Mackie et al., 1998), showing a tight phase locking at the tested frequencies of $130-135 \mathrm{~Hz}$ (Mackie et al., 1998); (2) produced spike bursting during stretching, a rapid drop in discharge on completion of the dynamic phase of stretching, and then a relatively slow drop during the holding phase (Matthews, 1933; Harvey and Matthews, 1961; Matthews, 1981; Edin and Vallbo, 1990); and (3) showed silenced firing during muscle shortening (stretch release) (Matthews, 1981; Edin and Vallbo, 1990; Grill and Hallet, 1995). It became clear during the first successful experiments in three distinct animals that cells responding in a 1:1 fashion to $130-135 \mathrm{~Hz}$ muscular sinusoidal vibration also responded to manual muscle stretch (by flexing or extending the appropriated articulation), showing bursting discharges during the dynamic phase of stretching followed by a fall in discharge rate during holding and silenced firing during shortening. Accordingly, we subsequently used manual muscular stretching to evoke all these patterns of discharge, and the neurons thus responding were assumed to receive spindle input. Further, in a different set of four animals, succinylcholine (SCh) chloride was injected through an external jugular vein $(300-500 \mu \mathrm{g} / \mathrm{kg}$ ) to test its effects on resting and sensory-evoked activity of cells showing the above patterns of discharge to manual stretching. In these same four animals, two stimulating electrodes separated $26-32 \mathrm{~mm}$ from each other were placed in the cervical ipsilateral dorsal column to drive cutaneous (at the middle dorsal cuneate region) and proprioceptive mvCN neurons at $50 \mathrm{~Hz}$ stimulation frequency. This served to compare first spike latencies and thus have an estimation of the conduction velocity of cutaneous and proprioceptive afferents reaching the middle main cuneate nucleus. Finally, in another set of three animals, the cellular sensitivity to different static positions from full extension to full flexion of the forelimb was ascertained by varying the angle of the elbow or wrist joints with the shoulder girdle immobilized using a homemade metal calibrated device and monitored with potentiometers over the axis of rotation.

The general experimental arrangement is diagrammatically schematized in Figure 1.

Histology. At the end of each experiment, positive current $(20 \mu \mathrm{A}$ for $20 \mathrm{~s})$ was passed through the stimulating and recording electrodes to mark their tip positions by electrolytic lesions. The animals were perfused with normal saline followed by $4 \%$ paraformaldehyde. The neural tissues of interest were removed and postfixed. Transverse $50 \mu \mathrm{m}$ frozen sections were cut, serially mounted, and stained with cresyl violet or neutral red, and the locations of recording and stimulating sites were determined.

Immunohistochemistry. During the course of the iontophoretic experiments, mvCN neurons showed glycine sensitivity blocked by the alkaloid strychnine (see Results). The inhibitory actions of glycine receptors (GlyRs) sensitive to strychnine acting as competitive antagonist (Young and Snyder, 1973) lead to an increased chloride conductance through a ligand-gated ion channel resulting in hyperpolarization of the postsynaptic membrane (Bormann et al., 1987). The strychninebinding site of the GlyR protein complex is located in the $\alpha 1-\alpha 4$-subunit variants, which constitute all GlyR isoforms (Becker, 1992). Because sensitivity to strychnine is indicative of $\alpha$-subunits being present, we decided to study whether cuneate neurons possessing GlyRs were differently distributed in the cutaneous core or cluster region relative to the $\mathrm{rvCN}$ and/or the mvCN. Two adult male cats $(3,5 \mathrm{~kg})$, different from those used for recording, were tranquilized with ketamine $(30 \mathrm{mg} / \mathrm{kg}$, i.m.), subsequently anesthetized with sodium pentobarbital $(60 \mathrm{mg} / \mathrm{kg}$, i.v. $)$, and intracardially perfused with $2 \mathrm{~L}$ of $0.9 \% \mathrm{NaCl}$ solution and $3 \mathrm{~L}$ of $4 \%$ paraformaldehyde in PBS, $\mathrm{pH}$ 7.4. The brains and spinal cords were rapidly removed, dissected, postfixed for $4 \mathrm{~h}$ in the same solution of $4 \%$ paraformaldehyde in PBS at $4^{\circ} \mathrm{C}$, and cryoprotected in $30 \%$ sucrose for several days. Fifty-micrometer coronal sections were cut on a cryostatmicrotome and stored in $30 \%$ glycerol in PBS at $4^{\circ} \mathrm{C}$ until use.

For immunohistochemical staining, the sections were processed as previously described (Darstein et al., 2000). In brief, free-floating sections were washed three times in PBS and pretreated in PBS with $0.3 \%$ $\mathrm{H}_{2} \mathrm{O}_{2}$ for $10 \mathrm{~min}$ to inhibit endogenous peroxidases. Sections were blocked by $2.5 \%$ horse serum, $0.3 \%$ Triton X-100, and $1 \%$ bovine serum 
albumin in PBS for $1 \mathrm{~h}$ at room temperature. Next, the sections were rinsed in PBS and incubated with the mouse GlyR antibody mAb4a at $4^{\circ} \mathrm{C}$ for $2 \mathrm{~d}$ (dilution 1:1000 in PBS containing $2.5 \%$ horse serum, $0.2 \%$ Triton $\mathrm{X}-100$, and $1 \%$ bovine serum albumin). Afterward, the sections were washed in PBS and incubated with a biotinylated anti-mouse antibody (dilution 1:400) at room temperature for $40 \mathrm{~min}$. Immunohistochemical staining was visualized using the avidin-biotin-peroxidase complex and 3,3diaminobenzidine tetrahydrochloride (DAB). Nickel ammonium sulfate was added to DAB solution to produce an intense blue-black reaction product. Sections were then mounted on gelatin chrome/alum-coated slides, dehydrated through a graded alcohol series, cleared with xylene, coverslipped with DPX. Control sections were processed to determine nonspecific staining by using the same procedure detailed above except that the primary antibody was omitted. The sections were viewed, analyzed, and photographed with a light microscope fitted with a digital camera. Four coronal sections at each rostrocaudal level were used for measurements. The dorsal and ventral regions of the rostral and middle $\mathrm{CN}$ were outlined in both left and right sides, and total areas were measured. The number and size of all GlyR Mab4a-immunoreactive neurons within each region were determined with the aid of image analysis software (NIS-D Elements, Nikon). Nonparametric one-way ANOVA (Kruskal-Wallis) and post hoc analysis (Dunn's multiple-comparison test) were used to analyze both the cell's size and the density of labeled cells per unit area. A probability value of $p<0.05$ was considered statistically significant.

\section{Results}

\section{Characterization of}

\section{proprioceptive neurons}

The neurons selected for study were driven by muscular manipulation responding briskly to pressing the muscle, but not the overlying skin or the related joints. Activity was maintained through the angular range of the joint, including midrange positions. The discharge rate increased with rotation in only one direction about a joint, and movement in the opposite direction led to a transient, velocity-dependent suppression of the discharge, with the subsequent rate reflecting the end position of the limb. We selected neurons highly sensitive to steady stretch and to sinusoidal vibrations applied over the region of maximal muscular sensitivity, and responding to muscle stretching with bursting discharges during the dynamic phase of stretching followed by a fall in discharge rate during holding, and silenced firing during the release phase of muscle stretch. Further, intravenous injection of SCh increased the activity of all 12 neurons tested (see below). These response properties strongly suggest that spindle primary afferent fibers were likely the primary source of excitatory drive. The data shown in Figure 2 illustrate the behavior of two different CL cells, both recorded $1 \mathrm{~mm}$ caudal and $2 \mathrm{~mm}$ lateral to the obex at depths of $1.8 \mathrm{~mm}$ and $2.2 \mathrm{~mm}$ from the surface, in response to passive joint movements and to sinusoidal vibration.
A1

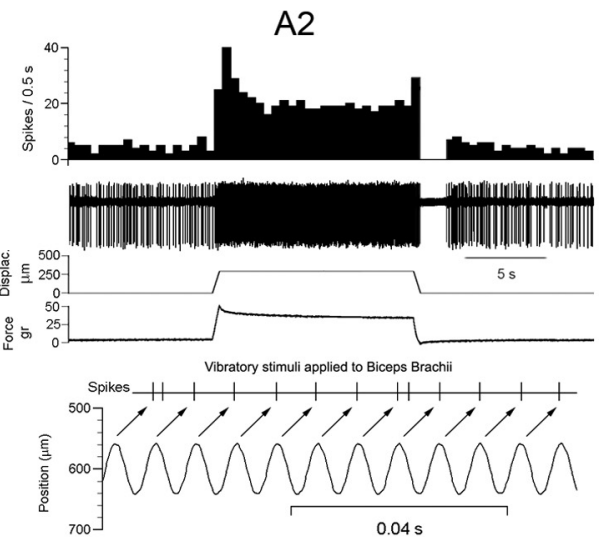

B2
B1

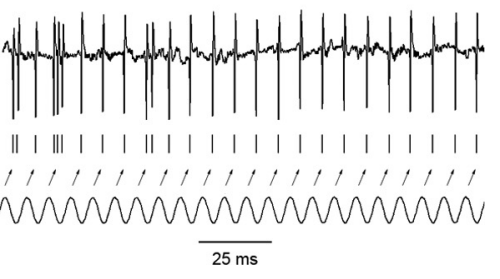

Vibratory stimuli applied to extensor carpi Ulnaris

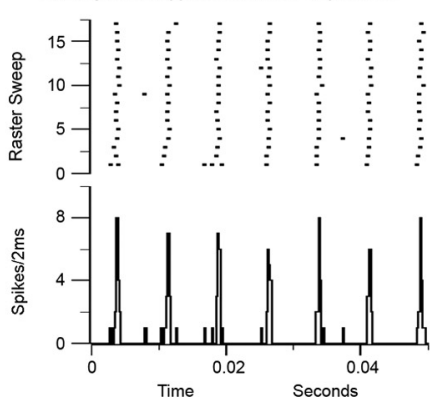

Figure 2. Characterization of proprioceptive mvCN neurons. Two different $\mathrm{CL}$ cells are illustrated $(\boldsymbol{A}, \boldsymbol{B})$. $\boldsymbol{A} \mathbf{1}$, Antidromic idenspontaneous spikes (SP) at the adequate interval (left panel). The arrows point to the ML stimulus artifacts. A2, This neuron was the by tapping the biceps brachii with a feedback mechanical stimulator at low and high frequencies. The records show the responses, and sinusoidal probe vibration at $135 \mathrm{~Hz}$. The arrows point to the spike responses produced by each sinusoid. $\boldsymbol{B}, \mathrm{A}$ different $\mathrm{CL}$ cell was activated by wrist flexion and by tapping the extensor carpi ulnaris at low (B1) and high (B2) frequencies. Note in the histogram and corresponding raster plot of $\boldsymbol{B} \boldsymbol{2}$ the tight coupling between the positive sinusoidal peaks, beginning at time were applied, and each dot represents a spike.

Because our main interest was to study the intracuneate circuitry implicated in the transmission of proprioceptive information, we did not perform muscle isolation or denervation, since these procedures might, within minutes, reorganize the spatiotemporal attributes of dorsal column nuclei neurons (Dostrovsky et al., 1976; Millar et al., 1976; Pettit and Schwark, 1993; Panetsos et al., 1995). Instead, we conducted experiments on four additional cats to study whether intravenous injection of SCh activated mvCN proprioceptive cells at rest and during manual muscular stretching and thus evaluate whether our previous sorting criteria were adequate to distinguish cells sensitive to primary spindle afferents.

SCh injection was tested on the activity of $12 \mathrm{mvCN}$ projection neurons, with 6 of them greatly increasing their resting activity (Fig. $3 A, B$ ) without apparent frequency variation during dynamic stretching. The responses to stretch were obtained during a period of $10-20 \mathrm{~s}$ after the maximal response to SCh. Four 
A
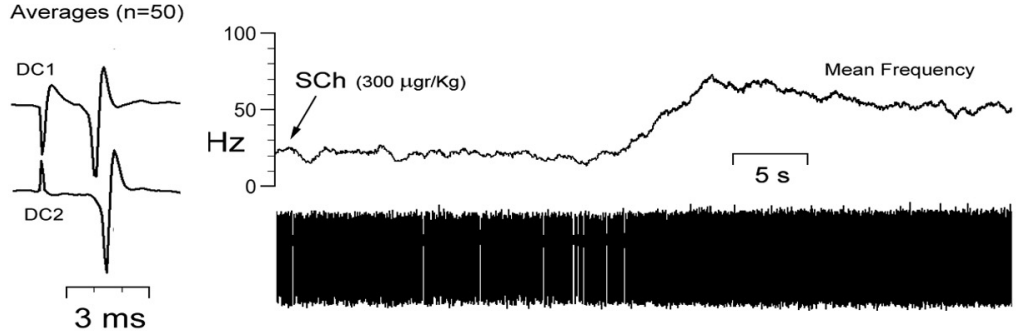

B
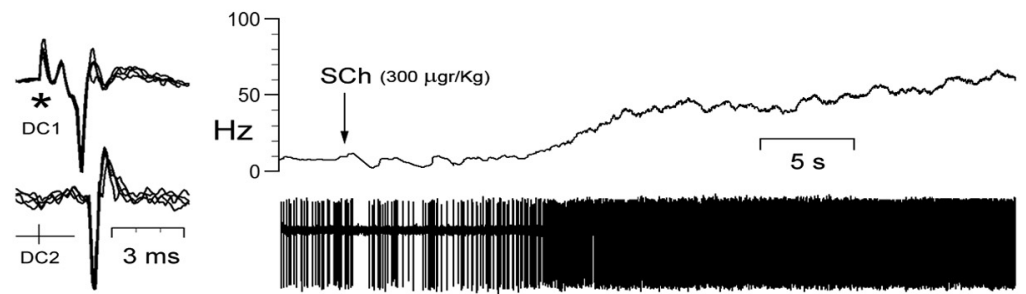

C
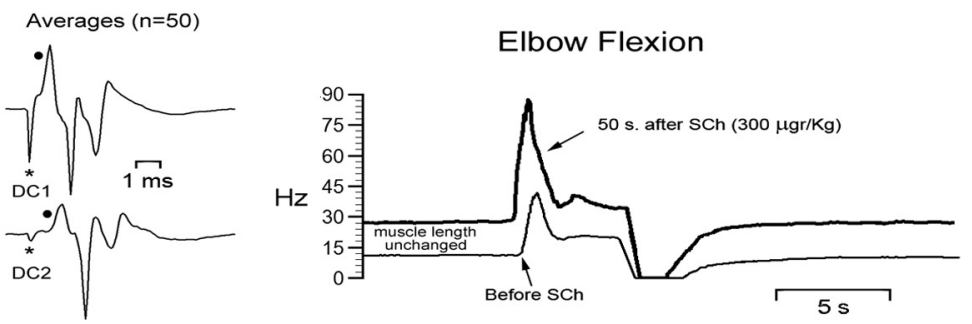

$\mathrm{D}$
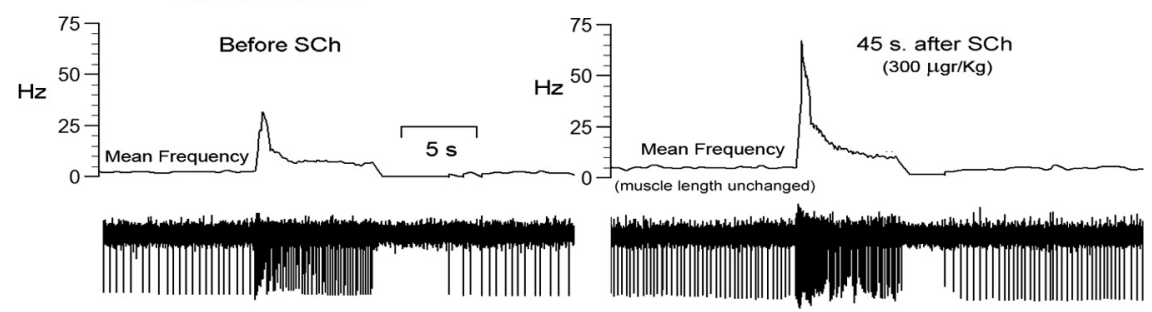

Figure 3. Sensitivity of mvCN neurons to intravenous injection of $S C h$. $A-D$, Four different cells. $A, B$, Resting activity, with muscle length unchanged, was greatly increased following $S C h$ injection. The insets at left show averages $(\boldsymbol{A})$ and single-sweep superimpositions $(\boldsymbol{B})$ of responses to two-point stimulation at the ipsilateral cervical dorsal column $(D C 1 ; D C 2)$. C , The resting (static) and dynamic activity to elbow flexion of a different $\mathrm{mvCN}$ cell were increased after $S C h$ injection. The inset at left shows the averages of 50 responses to two-point dorsal column stimulation with the black dots signaling positive field potentials reflecting the arrival of presynaptic volleys (Andersen et al., 1964a). D, Another mvCN cell showing a significant increase in activity during the dynamic phase of wrist flexion, while resting activity increased very little after $\mathrm{SCh}$ injection.

of the remaining six cells showed moderate increases in resting activity ( $15-25$ spikes/s) and clearly increased bursting during the dynamic phase of stretch after SCh (30-45 spikes/s) (Fig. 3C), and the last two neurons showed small increases in resting activity (3.5 and 5 spikes/s) but a clear bursting increment during the dynamic stretch (33 and 45 spikes/s) and silencing during shortening (Fig. 3D). Measures of increments in initial frequency and dynamic difference (peak frequency minus initial frequency) after SCh were taken as indices of effects exerted through static and dynamic primary spindle afferents, respectively (for a detailed description, see Taylor et al., 1992; Durbaba et al., 2006). In so doing, six neurons were considered to be affected by static bag2 primary spindle afferents, four cells by static/dynamic (bag1/ bag2) primaries, and two neurons by dynamic bag1 primary spindle afferents. Conduction velocities of the afferents driving these 12 neurons, tested by first spike latency following two-point stimulation at the ipsilateral cervical dorsal column, ranged between 59 and $70 \mathrm{~m} / \mathrm{s}$.

\section{Dataset}

The proprioceptive cells were found deep in the $\mathrm{mvCN}$ (mean \pm SD: $1.7 \pm 0.62 \mathrm{~mm}$ depth from the dorsal surface; $n=220$ ) and in the $\operatorname{rvCN}(1.25 \pm 0.63 \mathrm{~mm} ; n=$ 78). All neurons in the sample were activated by movement around a single joint: $112 / 278$ to elbow $(40.3 \% ; 80 \mathrm{mvCN}, 32$ $\mathrm{rvCN}), 84$ to wrist $(30.2 \%$; $63 \mathrm{mvCN}$, $21 \mathrm{rvCN}$ ), 61 to digits (22\%; $45 \mathrm{mvCN}, 16$ $\operatorname{rvCN})$, and 21 to shoulder $(7.5 \% ; 12$ $\mathrm{mvCN}, 9 \mathrm{rvCN})$. Neurons responded to extension (130/278: 47\%, $32 \mathrm{rvCN}$ ) and flexion in similar percentages.

The great majority of neurons recorded in the mvCN responded antidromically to ML stimulation (188/220: $85 \%)$. Different samples of these CL cells were tested to electrical stimulation of contralateral cerebral motor cortex and proprioceptive area 3a (Table 1); and of ipsilateral NRGc, MLR, and $\operatorname{rvCN}(n=52)$. In addition, the spontaneous and/or evoked activity of 56 mvCN cells (37 CL) were tested to microiontophoretic application of GABA $(n=26,18 \mathrm{CL})$ and/or glycine $(n=30$, $19 \mathrm{CL}$ ) and their antagonists bicuculline and strychnine, respectively.

From a total of 78 proprioceptive neurons recorded in the rvCN (5 CL: $\sim 6.5 \%$ ), 46 were tested to contralateral motor cortex and area 3 a stimulation (Table 1), and 37 were simultaneously recorded with $52 \mathrm{mvCN}$ cells $(13 \mathrm{rvCN}$ and $20 \mathrm{mvCN}$ cells with overlapping excitatory receptive fields; 24 rvCN and $32 \mathrm{mvCN}$ cells with unmatched excitatory receptive fields).

\section{Responses to cortical, ML, NRGc, MLR, and dorsal column electrical stimulation \\ Cerebral cortex}

Table 1 summarizes the cell responses to contralateral stimulation at the lateral tip of the cruciate sulcus (motor cortex) and at the postcruciate dimple (presumed area 3a) (schematically drawn in Figs. 1 and $4 A$ ). Most rvCN and mvCN proprioceptive neurons responded to cortical stimulation at similar latencies, and either with increases or decreases in firing rate. Cells responding with increases in firing showed longer latencies to area 3a stimulation (mean $8.6 \pm 2.8 \mathrm{~ms}$ ) than to motor cortex stimulation (mean $5.5 \pm 1.6 \mathrm{~ms}$ ) (histogram of Fig. $4 A)$, the difference being statistically significant $(p<0.001$; Mann-Whitney $U$ test). All 22 cells activated in response to both stimulating cortical sites (Table 1) also had greater latencies to area $3 \mathrm{a}$ than to motor cortex stimulation (mean difference $3.6 \pm 1.5 \mathrm{~ms}$ ) (see superimposed single sweeps in Fig. $4 \mathrm{~A})$. Likewise, cells responding with decreases in firing to cortical stimulation had longer latency responses to area $3 \mathrm{a}$ than to motor cortex stimulation (average difference of $5 \pm 2.2 \mathrm{~ms}$; $p<0.001$, Mann-Whitney). 
Table 1. Responses of mvCN and rvCN cells to cerebral cortical stimulation

\begin{tabular}{|c|c|c|c|c|c|c|c|c|c|}
\hline & \multirow[b]{2}{*}{ Tested } & \multirow[b]{2}{*}{ Responded } & \multirow[b]{2}{*}{ Antidromic to ML (CL cells) } & \multicolumn{2}{|c|}{ Motor cortex alone } & \multicolumn{2}{|l|}{ Area 3a alone } & \multicolumn{2}{|l|}{$M C x+3 a$} \\
\hline & & & & Firing increase & Firing decrease & Firing increase & Firing decrease & Firing increase & Firing decrease \\
\hline \multirow[t]{2}{*}{$\mathrm{mvCN}$} & 103 & $96(93 \%)$ & $58(56.3 \%)$ & $38(36.9 \%)$ & $12(11.6 \%)$ & $15(14.6 \%)$ & $8(7.8 \%)$ & $16(15.5 \%)$ & $7(6.8 \%)$ \\
\hline & & & & $27 \mathrm{CL}$ & $7 \mathrm{CL}$ & $9 \mathrm{CL}$ & $3 \mathrm{CL}$ & $8 \mathrm{CL}$ & $4 \mathrm{CL}$ \\
\hline \multirow[t]{2}{*}{$\mathrm{rvCN}$} & 46 & $33(72 \%)$ & $3(6.5 \%)$ & $9(19.6 \%)$ & $7(15.2 \%)$ & $5(10.9 \%)$ & $3(6.5 \%)$ & $6(13 \%)$ & $4(8.7 \%)$ \\
\hline & & & & $1 \mathrm{CL}$ & & $1 \mathrm{CL}$ & & $1 \mathrm{CL}$ & \\
\hline Total & 149 & $129(86.6 \%)$ & $61(41 \%)$ & $47(31.5 \%)$ & $19(12.7 \%)$ & $20(13.4 \%)$ & $11(7.4 \%)$ & $22(14.8 \%)$ & $11(7.4 \%)$ \\
\hline
\end{tabular}

A

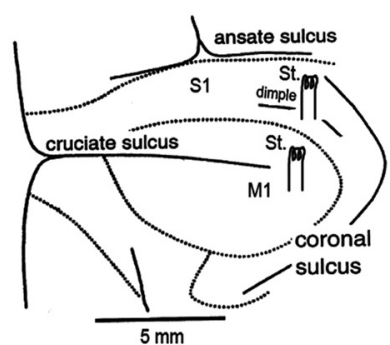

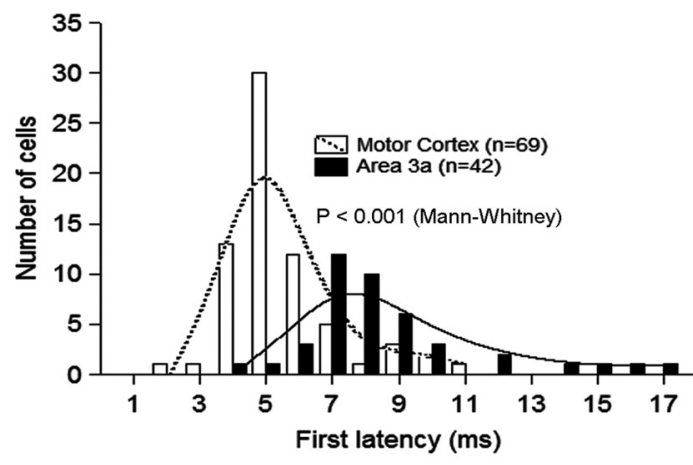

3. NRGC

B 1. ML

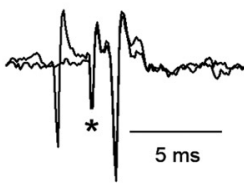<smiles>Cc1ccc(N(CC(C)C)OCCNC(C)C)cc1</smiles>

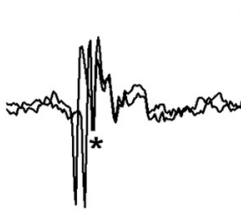

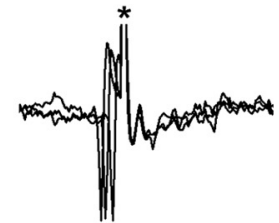

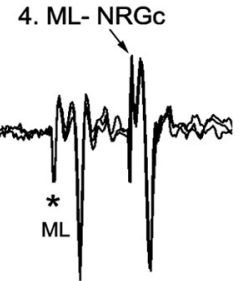

4. ML- NRGC<smiles>Cc1ccc(CNC(=O)OCc2ccccc2)cc1</smiles>

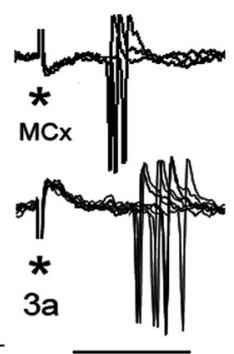

$10 \mathrm{~ms}$

\section{ML-MLR}
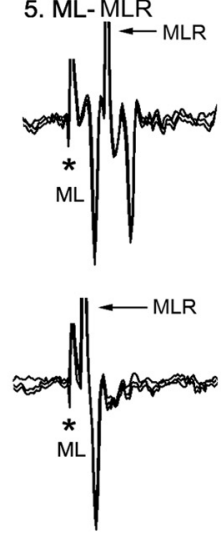

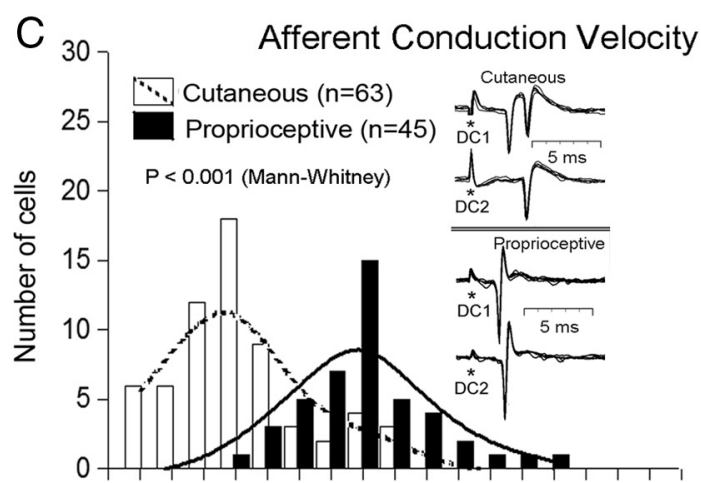

$17,527,537,547,557,567,577,5$

Conduction velocity $(\mathrm{m} / \mathrm{s})$

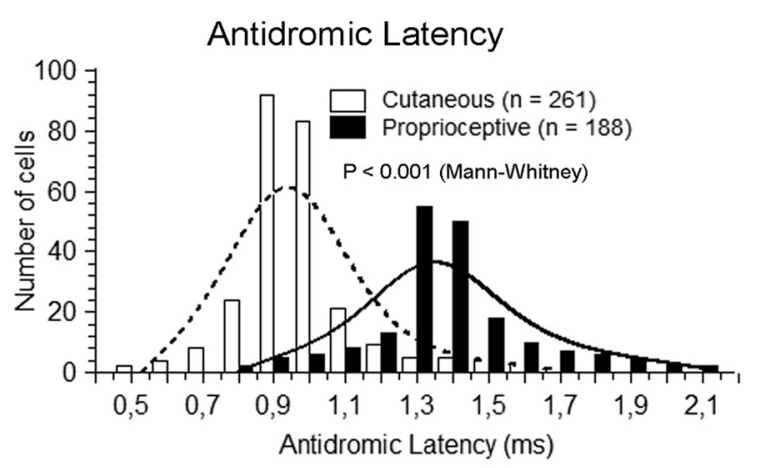

Figure 4. Motor cortex stimulation activated mvCN-CL cells at shorter latencies than area 3a. The mvCN projection neurons sent collateral branches to the ipsilateral NRGc and MLR, and showed shorter afferent and longer antidromic latencies than cutaneous $(\mathrm{L}$ neurons from the cluster region. $A$, Schematic drawing of stimulating electrodes placed in the cerebral cortex (left). The histograms illustrate the response latencies to motor cortex and area $3 \mathrm{a}$ stimulation with a sample of superimposed sweeps shown at right. The first latency data to motor cortex and area $3 \mathrm{a}$ stimulation well fit to two Gaussian distributions centered at 5 and $8 \mathrm{~ms}$, respectively. $\boldsymbol{B}$, Superimposed records illustrating a CL neuron sending a collateral branch to or through the NRGc and the MLR with the antidromic responses shown in the upper part and collision with spontaneous or evoked spikes in the lower part of each panel (1-3). Reciprocal ML-NRGc and ML-MLR collision tests are shown in panels 4 and 5 , as indicated. Stimulus artifacts are marked by asterisks. In panel 5 , the polarity of ML stimulation was reversed. C, Histogram showing the bimodal Gaussian distributions of cutaneous cells from the cluster region and mvCN proprioceptive neurons, grouped according to the conduction velocities of afferent fibers driving them (bins of $5 \mathrm{~m} / \mathrm{s}$ ). The single-sweep superimpositions at the inset show examples of afferent-induced responses generated on one cutaneous (top) and one proprioceptive (bottom) cells. $\boldsymbol{D}$, Histograms of the antidromic latencies of cutaneous and proprioceptive $\mathrm{CL}$ cells recorded in the cluster region and mvCN, respectively. Their distribution is bimodal and well fit by two Gaussian graphs centered at 0.95 and $1.35 \mathrm{~ms}$. 
Table 2. Cutaneous versus proprioceptive properties of $\mathrm{CL}$ neurons at the middle main cuneate nucleus

\begin{tabular}{|c|c|c|c|c|c|c|}
\hline & \multirow[b]{2}{*}{ Main location } & \multicolumn{2}{|l|}{ Mean CV $(\mathrm{m} / \mathrm{s})$} & \multirow[b]{2}{*}{ GABA } & \multirow[b]{2}{*}{ Glycine } & \multirow[b]{2}{*}{ Ipsilateral collaterals } \\
\hline & & ML antidromic & Afferent & & & \\
\hline Cutaneous & $\mathrm{mdCN}$ & $20 \pm 4.5$ & $48.3 \pm 13.4$ & Inhibition & Disinhibition & Not reported \\
\hline Proprioceptive & $\mathrm{mvCN}$ & $14.3 \pm 2.6$ & $62.5 \pm 11.1$ & Inhibition & Inhibition & Yes \\
\hline
\end{tabular}

CV, Conduction velocity; mdCN, middle dorsal cuneate nucleus.

A

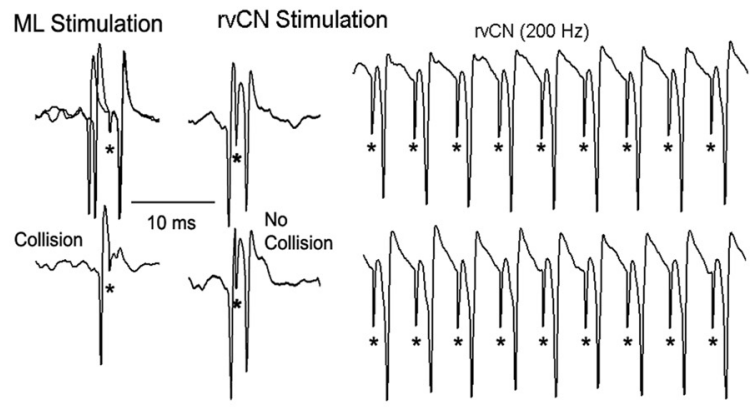

Wrist Extension

$\operatorname{rvCN}$

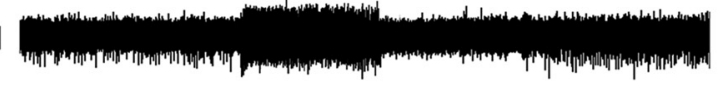

mVCN

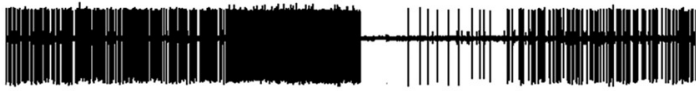

$10 \mathrm{~s}$
B ML Stimulation
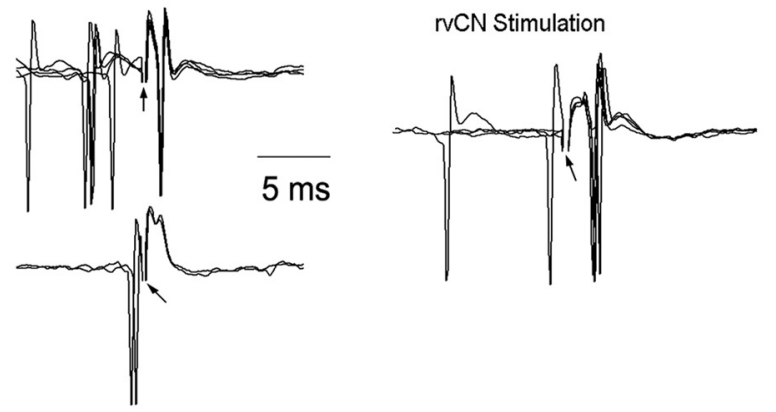

Wrist Flexion

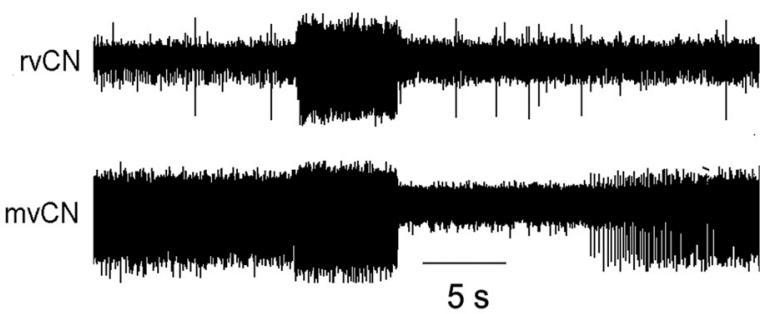

C

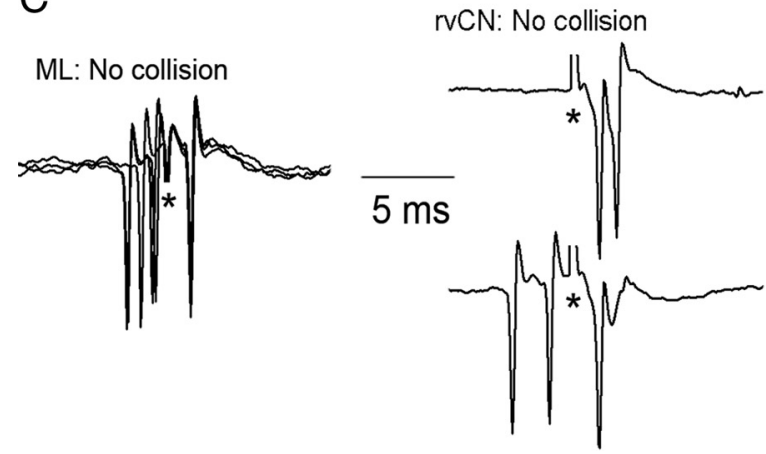

rvCN. $100 \mathrm{~Hz}$

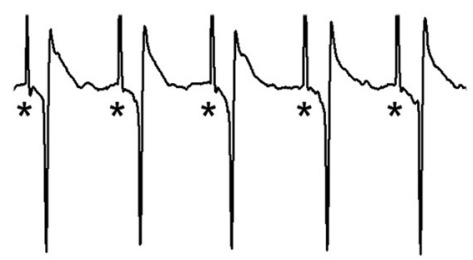

Elbow Extension
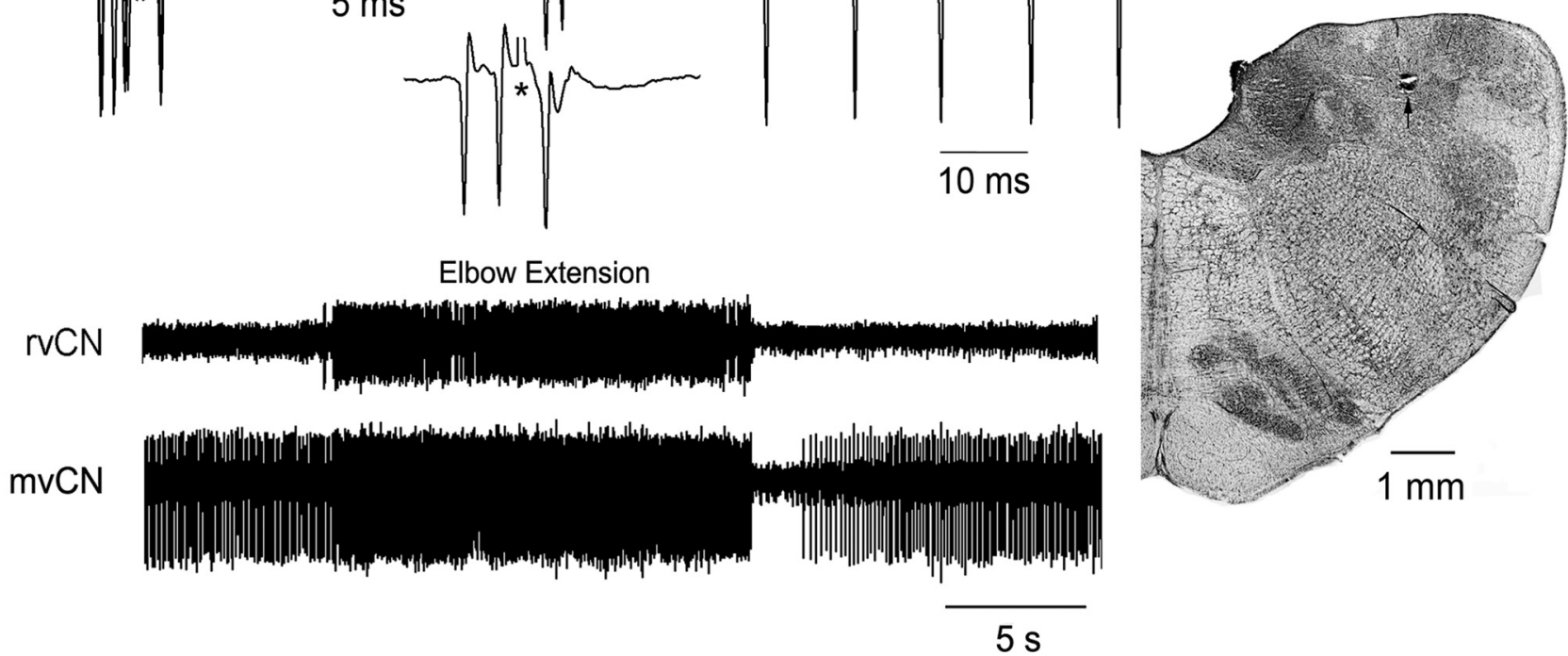

Figure 5. Dual recordings demonstrated that whenever mvCN and rvCN neurons had excitatory receptive fields at the same joint, rvCN microstimulation activated mvCN cells. The records illustrate the behavior of two $\mathrm{CL}$ cells $(\boldsymbol{A}, \boldsymbol{B})$ and one non- $\mathrm{CL}$ neuron $(\boldsymbol{C})$. $\boldsymbol{A}$, An ML-antidromic mvCN neuron (upper left, antidromic identification) responding to wrist extension was orthodromically activated by stimulation at an rvCN site also activated by wrist extension (lower records). Note that the mvCN cell faithfully followed $200 \mathrm{~Hz}$ rvCN repetitive stimulation, but collision did not occur (upper). $\boldsymbol{B}$, Another $\mathrm{C}$ neuron (upper left, antidromic identification) responding to wrist flexion was orthodromically activated (upper right, superimposed sweeps) by stimulating an rvCN site also activated by wrist flexion (lower records). C, A non-CL mvCN neuron (upper left, no collision) sensitive to elbow extension (lower) was orthodromically activated by stimulating at an rvCN site (upper, right two panels) also sensitive to elbow extension (lower). Note that the mvCN cell followed $100 \mathrm{Hziterative} \mathrm{rvCN} \mathrm{stimulation,} \mathrm{but} \mathrm{collision} \mathrm{did} \mathrm{not} \mathrm{occur} \mathrm{(upper} \mathrm{right).} \mathrm{An} \mathrm{electrolytic} \mathrm{lesion} \mathrm{(signaled}$ by an arrow) produced at this stimulating rvCN site is shown at right. Stimulus artifacts are marked by asterisks. 
A1
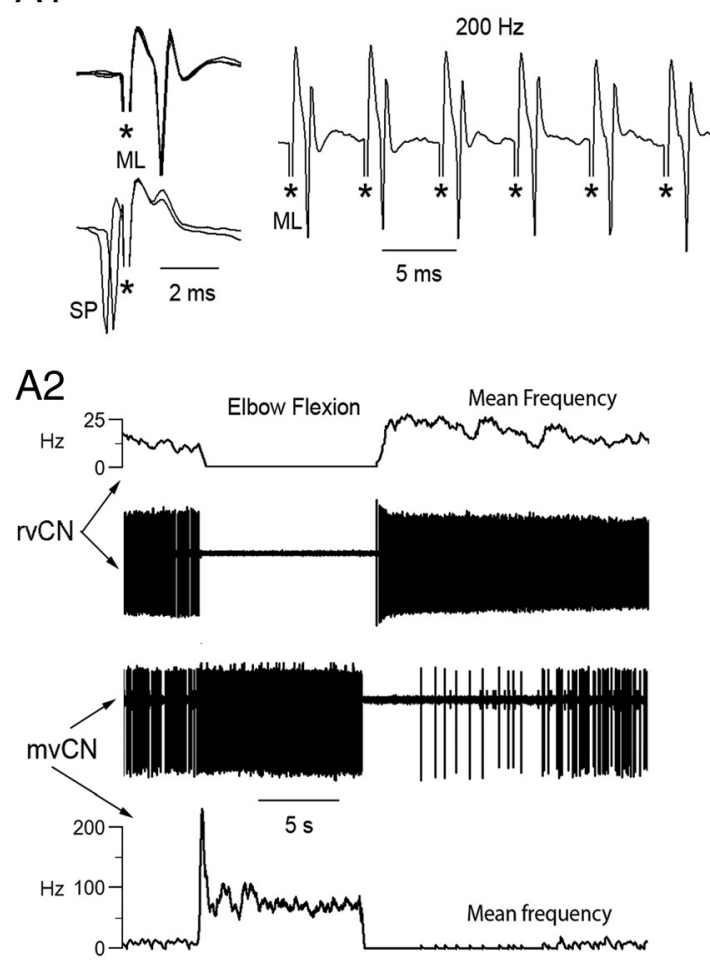

\section{B1}
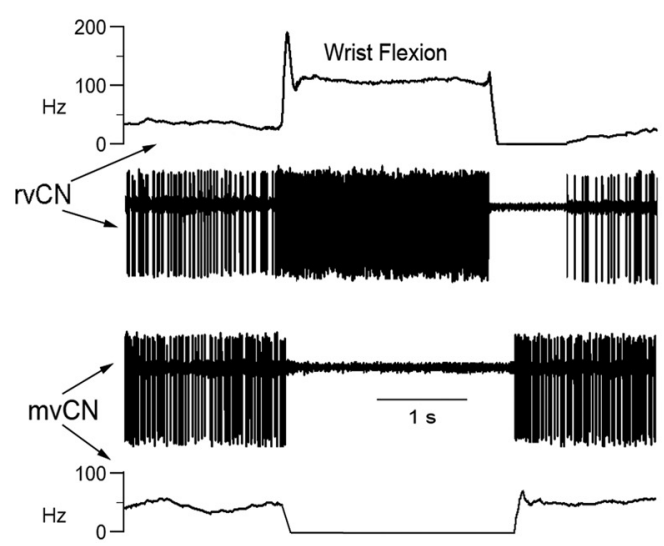

\section{B2}
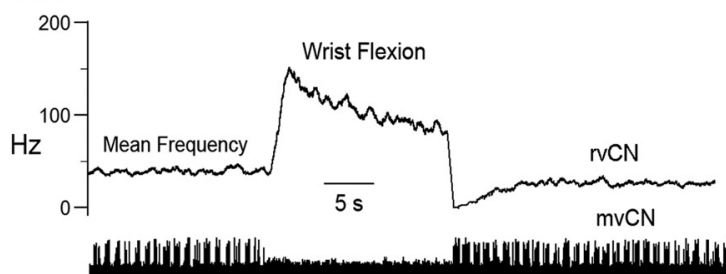

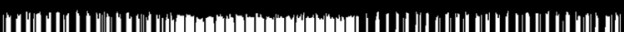
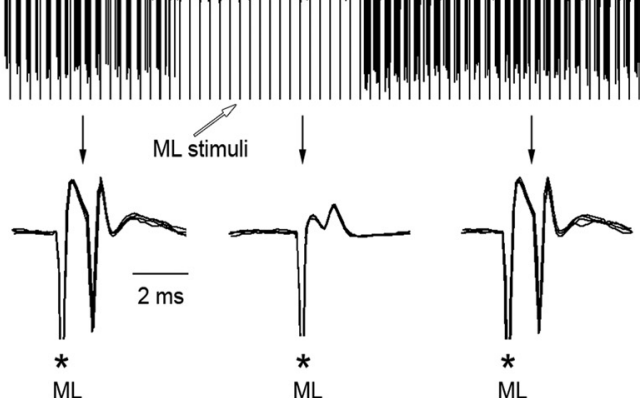

B3

rvCN stimulus ( $75 \mu \mathrm{A} ; 10$ superimpositions)

$\operatorname{mvCN}$
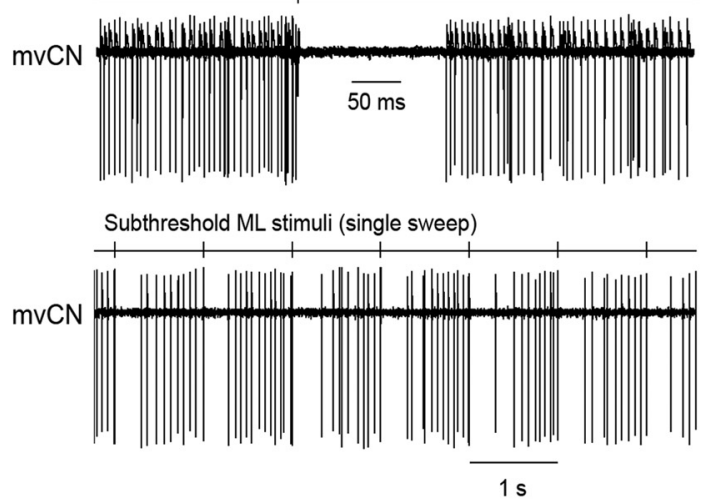

B4

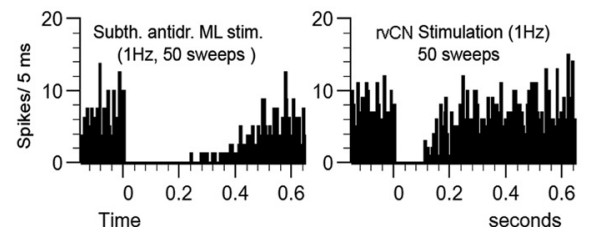

Figure 6. When simultaneously recorded mvCN and rvCN neurons had receptive fields in distinct articulations, stimulation at the rvCN site inhibited the concurrently recorded mvCN cell. $\boldsymbol{A}, \boldsymbol{B}, \mathrm{T}$ wo different cells. $\boldsymbol{A}$, Antidromic identification of a $\mathrm{CL}$ neuron $(\boldsymbol{A} \mathbf{1})$ activated by elbow flexion ( $\boldsymbol{A} \mathbf{2}$, lower). Elbow flexion inhibited another concurrently recorded rvCN cell ( $\boldsymbol{A} \mathbf{2}$, upper). $\boldsymbol{B}$, Wrist flexion activated an rvCN neuron and inhibited a simultaneously recorded mvCN-CL (B1). The antidromic spikes of the CL cell failed during wrist flexion (B2, superimposed sweeps expanded below), indicating that wrist flexion exerted a true inhibition on the mvCN neuron. Microstimulation at the rvCN recording site transitorily suppressed the activity of the mvCN cell ( $B 3$, upper). Subthreshold ML stimulation also transiently silenced the mvCN neuron ( $B 3$, lower). The peristimulus histograms in $B 4$ (stimuli at time 0 ) show that the ML induced inhibition was longer lasting than the rvCN inhibition. Stimulus artifacts are marked with asterisks in $\boldsymbol{A}$ and the expanded records in $B 2$; the stimulus artifacts in $B \mathbf{B}$ were recorded on a different channel shown above each neuronal recording.

Medial lemniscus, NRGc, MLR, and dorsal column

The great majority of the proprioceptive CL neurons were located in the mvCN. A total of 52 of these cells were tested to NRGc, MLR, and rvCN stimulation; 21 of them (40.4\%) responded antidromically to NRGc, MLR stimulation fired antidromically 2 cells $(3.8 \%)$, and 8 cells were antidromically fired from both structures (15.4\%). No mvCN-CL cells were antidromically fired from the rvCN. Thus, $\sim 56 \%(29 / 52)$ and $\sim 19 \%(10 / 52)$ of the tested CL neurons sent collateral branches ending or passing through the ipsilateral reticular formation or the MLR, respectively. Figure $4 B$ illustrates the antidromic identification of a proprioceptive CL cell (Fig. 4B1) that collateralized to the NRGc (Fig. 4B4) and the MLR (Fig. 4B5). The upper records in each panel of Figure $4 B$ show the antidromic re- sponses; the lower records show the collision tests with orthodromic spikes (Fig. 4B1-B3) and the reciprocal collisions between the main axon and the collateral to the NRGc (Fig. 4B4), and the main axon and the collateral to the MLR (Fig. 4B5). These tests were performed with every neuron to determine the antidromic nature of the responses. Distance-threshold curves were performed by vertically moving the stimulating electrodes (as in Lamas et al., 1994), and the minimal thresholds for antidromic activation were located within the NRGc and the MLR (Fig. 1), thus raising the possibility that proprioceptive CL neuron collateral branches could terminate within ipsilateral regions producing and controlling movement. 
mvCN Non Lemniscal Cell

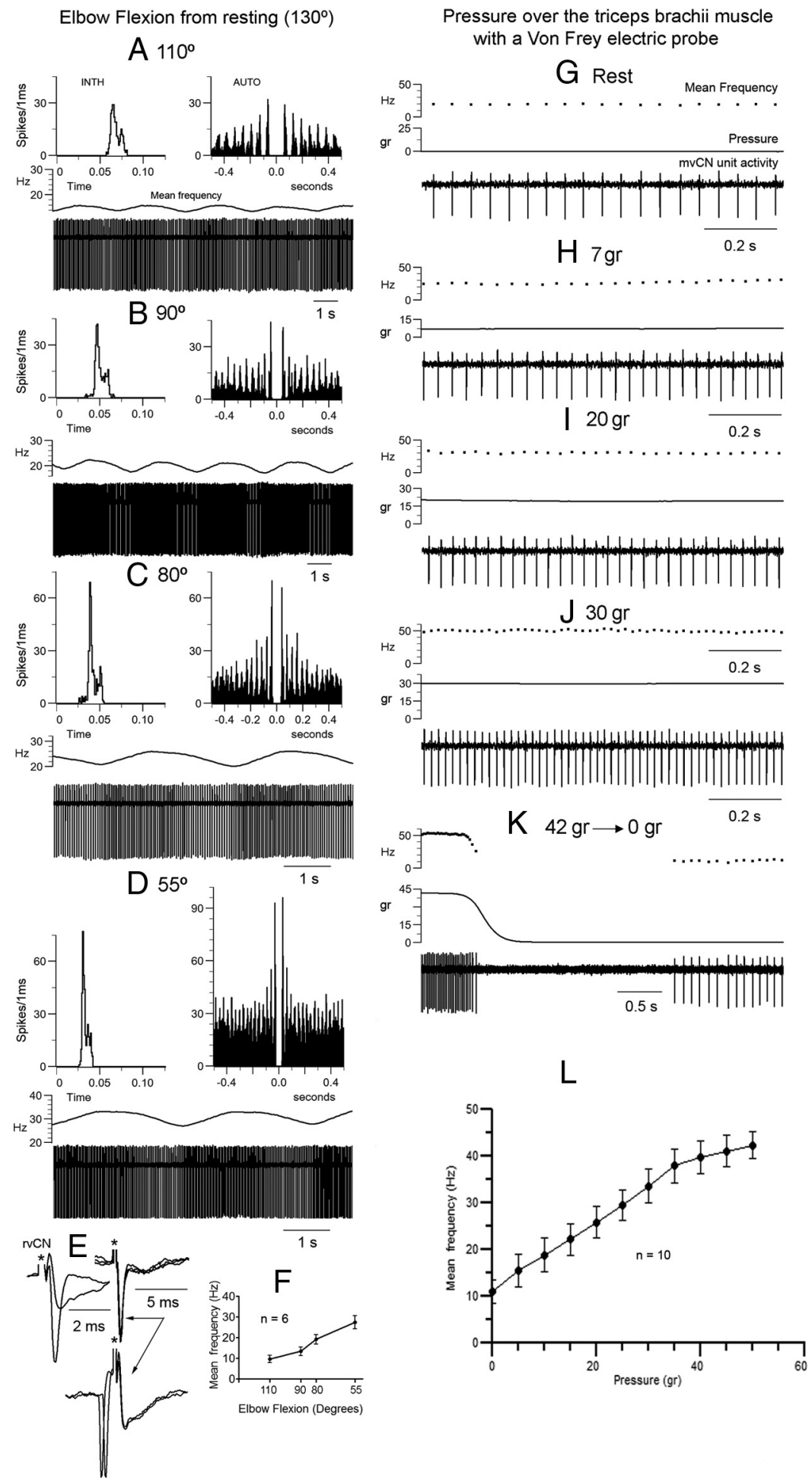

Figure 7. mvCN neurons were sensitive to muscle steady stretch. Same non- $C \mathrm{~L}$ neuron. $\boldsymbol{A}-\boldsymbol{D}$, This non- $\mathrm{CL}$ cell showed a slow rhythmic activity at $\sim 0.4 \mathrm{~Hz}$. The elbow joint was gradually flexed from rest $\left(130^{\circ}\right)$ and maintained at each new position for 5 min. The activity of the non- $\mathrm{CL}$ cell gradually incremented with lengthening of extensors. INTH, Interval interspike histogram; AUTO, autocorrelogram. $\boldsymbol{E}$, This presumed interneuron responded antidromically to rvCN stimulation. The two superimpositions at left show the all or none nature of the antidromic spike and the superimposed records at right illustrate the collision test. $\boldsymbol{F}$, Histogram (mean \pm SEM) showing an almost linear increase in activity with elbow flexion for six different cells (4 CL). $\mathbf{G}-\boldsymbol{K}$, Increasing the steady pressure applied to the triceps brachii produced a similar increase in frequency as that observed with steady stretch. Note the firing silence at the end of stimulation $(\boldsymbol{K})$. $\boldsymbol{L}$, Histogram illustrating the mean \pm SEM frequency increase with pressure for 10 different cells $(7 \mathrm{CL})$.
None of the non-CL neurons were antidromically fired from the tested sites.

The ML antidromic latencies of the 188 proprioceptive neurons were compared with the antidromic latencies of a different sample of 261 CL cells with cutaneous receptive fields recorded more dorsally, in the cluster region of the medial cuneate nucleus, in previous work from our laboratory (Aguilar et al., 2002, 2003; Soto et al., 2004, 2006). The antidromic latencies of these samples were significantly different ( $p<0.001$, Mann-Whitney). As shown graphically in Figure $4 D$, the mean antidromic latency of proprioceptive cells $(1.4 \pm 0.23 \mathrm{~ms})$ was longer than that of the cutaneous neurons $(1 \pm$ $0.19 \mathrm{~ms}$ ), the average antidromic conduction speed of the proprioceptive axons being $\sim 6 \mathrm{~m} / \mathrm{s}$ slower than that of the cutaneous axons (mean distance from the ML stimulating site to the cuneate recording, $20 \mathrm{~mm}$ ). The antidromic latencies were corrected neither for utilization time at the stimulus site nor for initial segmentsomatodendritic delay in soma invasion, which may significantly contribute to the antidromic latency, although probably of minor importance when dealing with latency differences using similar stimulating parameters.

A burst of 3-5 spikes followed the antidromic responses with a first spike latency varying between 9.5 and $12 \mathrm{~ms}$ to NRGc stimulation and between 10.5 and $16 \mathrm{~ms}$ to MLR stimulation. Twelve of the twenty-three cells not responding antidromically to NRGc did respond synaptically, producing a first spike at latencies varying between 2 and $5 \mathrm{~ms}$ and a second late burst of 3-5 spikes with a first spike latency varying between 9.5 and $12 \mathrm{~ms}$. A different sample of six cells ceased firing during the 40-80 ms following the NRGc stimuli, and another set of five neurons were not affected by NRGc stimulation. Ten of the forty-two non-antidromic cells to MLR stimulation increased activity, generating a first spike at latencies varying from 4.5 to $6 \mathrm{~ms}$ followed by a burst of 3-5 spikes with a first spike latency varying between 10.5 and $16 \mathrm{~ms}$; the firing of 12 different neurons was silenced during the 250-300 ms following MLR stimulation; and the other 20 cells were not affected by MLR stimulation.

Finally, in an independent sample, two-point stimulation at $50 \mathrm{~Hz}$ in the ipsilateral C2-C4 dorsal column revealed that the conduction velocity of cutaneous afferents driving neurons at the cluster region was slower $[33.5 \pm 11.5 \mathrm{~m} / \mathrm{s}$ $($ mean $\pm \mathrm{SD})$; range $15-58.5 \mathrm{~m} / \mathrm{s} ; n=63$ ] 
A mvCN Lemniscal Cells

Antidromic Identification

Control

$\mathrm{BiCu}(40 \mathrm{nA})$
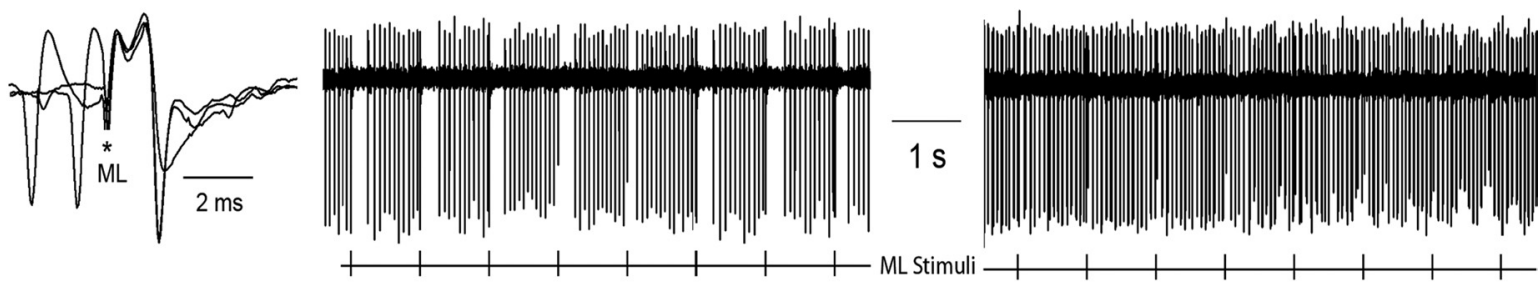

B

rvCN Stimulation

$(1 \mathrm{~Hz})$

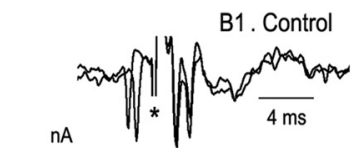

\section{C1 rvCN Stimulation $(1 \mathrm{~Hz}) .80$ Sweeps}
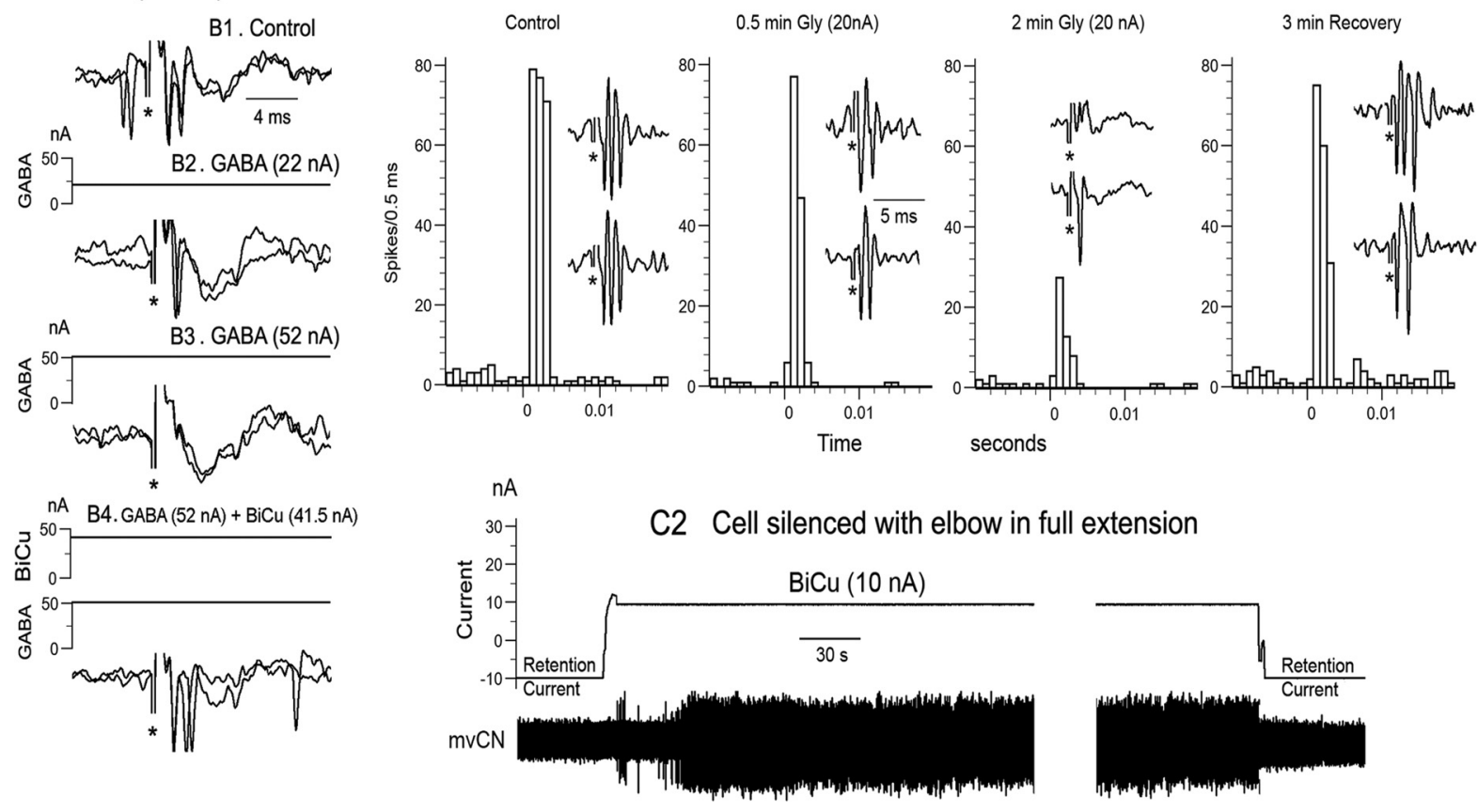

Figure 8. GABA and glycine shape the responses of mvCN projection cells. $A-C$, Three different $C L$ neurons. $A$, Antidromic identification (left) showing that collision occurred when a spontaneous spike preceded the antidromic response at the adequate interval. The single-sweep records show transient silenced firing following antidromic ML spikes (left sweep) that was abolished by BiCu ejection (right sweep). B, A different CL cell was orthodromically activated by rvCN stimulation (no collision in B1), and GABA ejection (52 nA) blocked the rvCN-induced excitation (B2, B3), an effect that was reversed by simultaneously ejecting BiCu (B4).C, Glycine blocked the rvCN-induced activation of another $\mathrm{CL}$ cell (C1). BiCu restored the cellular activity when suppressed by fully extending the elbow (C2). This cell increased firing when flexing the elbow.

than that of the proprioceptive afferents activating cells at the $\operatorname{mvCN}(52.5 \pm 9.4 \mathrm{~m} / \mathrm{s}$; range $35-82 \mathrm{~m} / \mathrm{s} ; n=45)$ (histogram and superimposition of single sweeps in Fig. $4 C$; see also the averaged records and superimposed single sweeps at the insets, at left, in Fig. 3A-C, for proprioceptive cells). Table 2 shows some of the distinctive properties of cutaneous and proprioceptive neurons at the middle main cuneate nucleus derived from the present and previous work (Aguilar et al., 2003).

Effects of rvCN microstimulation (50-150 $\mu \mathrm{A})$ at sites showing matched and nonmatched receptive fields with simultaneously recorded mvCN neurons

A total of 69 proprioceptive mvCN neurons (52 CL) were tested to ipsilateral rvCN stimulation. Two of them, both non-CL neurons, responded antidromically; 47 (38 CL) increased firing with first spike latency ranging from 0.3 to $3 \mathrm{~ms} ; 14$ (12 CL) decreased firing during the first 50-300 ms after the stimuli; and 6 (2 CL) were unresponsive. No CL cells were found to collateralize into the rvCN.

When performing rvCN and mvCN simultaneous recordings, the rvCN recording electrode could be switched to stim- ulation in an intermittent manner to test whether rvCN microstimulation in a region with a given proprioceptive field differentially affected mvCN cells with overlapping and nonoverlapping receptive fields. In this condition, both $\mathrm{rvCN}$ and mvCN cells showed excitatory fields ( $13 \mathrm{rvCN}$ and $20 \mathrm{mvCN}$ cells) exclusively when tapping muscles at one and the same articulation, independently of whether the fields were located within agonists or antagonists. In these cases, microstimulation through the rvCN recording electrode invariably incremented the activity of mvCN cells. This is illustrated in Figure 5 for two mvCN cells responding antidromically to ML (Fig. $5 A, B)$ and for a presumed mvCN interneuron (Fig. $5 C$ ). The rvCN-induced excitation could follow stimulating frequencies of up to $200 \mathrm{~Hz}$ (Fig. 5A) but the criteria for antidromic activation were met in only two cases in which collision with spontaneous or evoked orthodromic spikes could be demonstrated (see Fig. 7E). Increasing the rvCN stimulating current to $200-300 \mu \mathrm{A}$ (and thus the spread of current to neighboring sites), or slightly moving the stimulating electrode, varied the structure of the response producing at first an increase of 

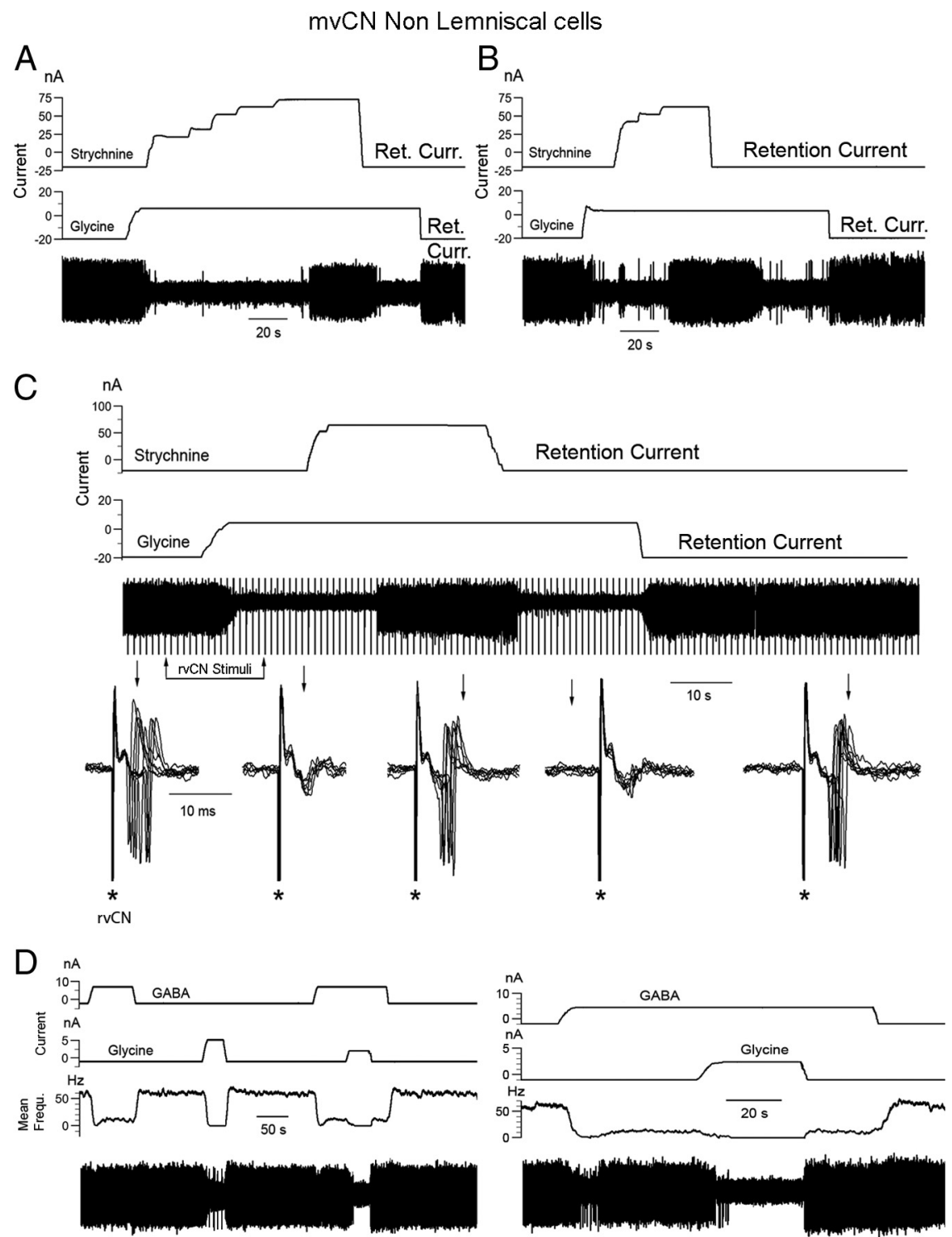

Figure 9. Effects of glycine, strychnine, and GABA on mvCN presumed interneurons. $\boldsymbol{A}-\boldsymbol{D}$, Four different spontaneously active non-CL cells. $A, B$, The suppression of spontaneous activity by glycine was abolished by concurrent strychnine ejection. $C$, The synaptic activation produced by rvCN stimulation (see the superimposed records expanded below) was abolished by glycine ejection and restored when simultaneously ejecting strychnine. $\boldsymbol{D}$, Additive effects on spontaneous activity by simultaneously ejecting GABA and glycine, as indicated.

firing followed by a period of silenced firing, thus suggesting a spatial specificity of effects.

Converse receptive rvCN and mvCN fields (for example, excitatory for one rvCN neuron, inhibitory for another mvCN cell simultaneously recorded) were observed solely when their excitatory receptive fields were located at muscles in different articulations (Fig. 6). In these cases, $10 \mathrm{rvCN}$ stimulating sites induced silenced firing on $14 \mathrm{mvCN}$ neurons during the $100-300 \mathrm{~ms}$ following the stimuli (Fig. 6B3,B4). In another sample, $14 \mathrm{rvCN}$ microstimulating sites with fields in articulations other than the fields of 18 simultaneously recorded mvCN cells induced increasing-decreasing sequences of $\mathrm{mvCN}$ firing. However, when vertically moving the rvCN electrode $30-50 \mu \mathrm{m}$, microstimulation at the new position varied the response of 6 of these 18 $\mathrm{mvCN}$ cells from increasing-decreasing sequences to a decrease of firing during the 100-300 ms following the stimuli, again suggesting a spatial specificity of effects. These silenced firings were due to a true inhibition, since ML antidromic invasion of the $\mathrm{mvCN}$ neurons failed during the firing suppression (Fig. $6 \mathrm{B2}$ ), suggesting that neuronal hyperpolarization might be the cause of silencing.

The data from these series strongly suggest that rvCN cells might function as interneurons, producing a double effect on mvCN proprioceptive CL cells: potentiation when the excitatory fields of rvCN interneurons and mvCN projection cells are located in muscles acting at the same joint, and inhibition when rvCN and mvCN neurons have excitatory receptive fields located in muscles acting at different joints.

\section{Sensitivity of proprioceptive cuneate cells to steady stretch}

Both CL and non-CL proprioceptive neurons showed properties similar to those of primary spindle afferents in relation to steady stretch (18 cells tested; $12 \mathrm{CL}$ ), a parameter directly influenced by joint angle and therefore with a tight coupling to limb position. Varying the joint angle produced steady increases in spike frequency during the intermediate range of joint movement and often silenced firing at the largest physiological angle of motion (for example, see Fig. 8C2), indicating that these neurons were probably not affected by joint receptors, since these are activated at the end positions of joint movement (Burgess and Clark, 1969; Clark and Burgess, 1975; McCloskey, 1978). A similar behavior was found when steadily tapping, with a Von Frey electrical probe, the region over a presumed muscle spindle that was most responsive for the cell under study. Figure 7 exemplifies these behaviors for one of the two presumed mvCN interneurons (did not respond antidromically to ML stimulation) that projected to the $\mathrm{rvCN}$ (antidromic identification in Fig. 7E).

Effects of microiontophoresed GABA and/or glycine

Microiontophoretic application of GABA and/or glycine consistently reduced or silenced the spontaneous and evoked activity of all $36 \mathrm{mvCN}$ proprioceptive cells tested, an effect that was reversed by $\mathrm{BiCu}$ or strychnine ejection, respectively. Examples of these effects are illustrated in Figures 8-10 for CL cells and non-CL cells or presumed interneurons. ML stimulation often produced an antidromic response followed by a period of silenced activity (Fig. $8 \mathrm{~A}$, Control). This presumed recurrent suppression (Kelly and Renaud, 1973; Canedo et al., 2000) was observed at stimulating frequencies of up to $20-25$ $\mathrm{Hz}$ and was canceled by application of $\mathrm{BiCu}$ (Fig. $8 \mathrm{~A}$, right) and/or strychnine. GABA (Fig. $8 B$ ) and glycine (Fig. $8 \mathrm{Cl}$ ) also suppressed the excitatory effects induced by rvCN stimulation, and $\mathrm{BiCu}$ (Fig. 8C2) and/or strychnine restored the ac- 
tivity of mvCN cells when concealed by appropriated full extension or flexion of a particular forelimb joint.

The suppression of spontaneous and evoked activity following glycine application is illustrated by the data shown in Figure 9 for 4 different non-CL cells $(A-D)$. Concurrent ejection of glycine and strychnine reversed the effect of glycine-alone application, restoring spontaneous (Fig. $9 A-C$ ) as well as stimulus-induced (Fig. $9 C$ for rvCN stimulation) activity. When adjusting the ejecting GABA or glycine currents to decrease spontaneous activity without annulling it, subsequent concurrent ejection of the other neurotransmitter silenced the eight tested cells (5 CL) (Fig. 9D). These same eight cells were also tested to concurrent ejection of GABA and glycine on the evoked responses to directly pressuring the related muscle over the more sensitive region encountered. In this condition, the bursting dynamic response was most resistant to GABA and/or glycine. Ejecting currents of up to $35 \mathrm{nA}$ for glycine-alone ejection and up to $50 \mathrm{nA}$ for GABA-alone ejection were necessary to completely suppress the sensoryevoked responses. Adjusting the ejecting current for one of the neurotransmitters (GABA or glycine) so that only the dynamic response remained, simultaneous ejection of the other neurotransmitter completely abolished the evoked response (Fig. 10A). The concurrent ejecting currents for GABA plus glycine suppressing the responses to sensory activation were $55 \pm 8.5 \%$ smaller, on average, than those necessary to obtain the same effect by ejecting either one of the neurotransmitters alone.

Finally, a tonic inhibitory effect on proprioceptive cells could be demonstrated for GABA and glycine. The data in Figure 10, $B$ and $C$, illustrate the effect for GABA. In this experiment, two stimulating electrodes $500 \mu \mathrm{m}$ apart were inserted into the rvCN, one producing an excitatory effect (rvCN2 in Fig. $10 \mathrm{~B}$; right panel, lower superimpositions) and the other producing no detectable effect (rvCN1 in Fig. 10 B; right panel upper superimpositions). When subthreshold stimulation was applied through the rvCN2 electrode (Fig. 10C, left panel), concurrent $\mathrm{BiCu}$ ejection converted subthreshold stimulation to suprathreshold (Fig. $10 C$, center and right panels). $\mathrm{BiCu}$ and/or strychnine ejection increased the spontaneous resting activity of all 14 tested cells, pointing to a tonic inhibition exerted by both GABA and glycine on CL proprioceptive mvCN neurons.

\section{Immunohistochemistry}

Round GlyR-immunoreactive neurons in the middle dorsal cuneate nucleus were arranged in a circular fashion around a central clustered area, whereas triangular, multipolar, and fusiform GlyR-positive neurons not arranged in clusters characterized the mvCN (see Fig. 11A). GlyR mAb4a-positive neurons were dis-
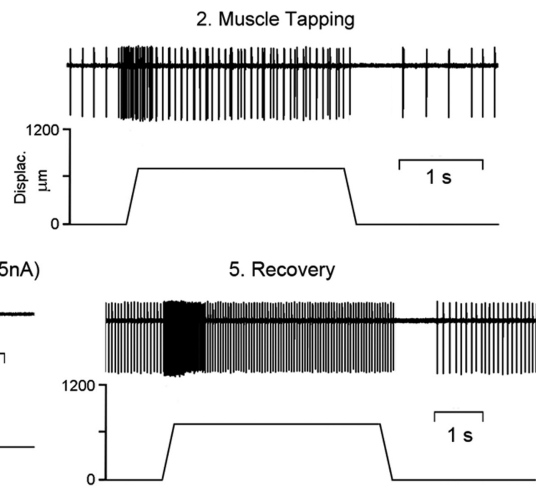

4. GABA $(12 n A)+$ Glycine $(5 n A)$
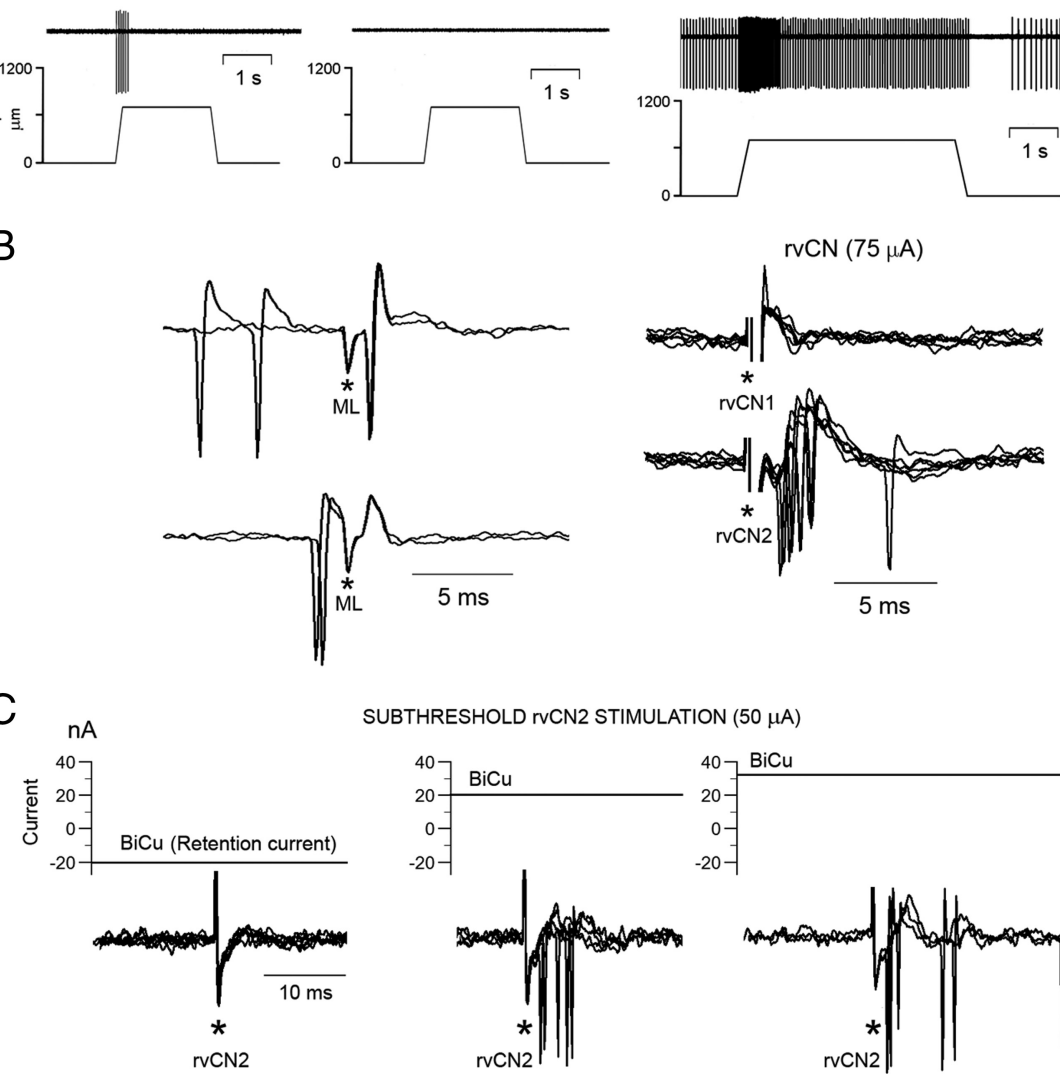

SUBTHRESHOLD IVCN2 STIMULATION $(50 \mu \mathrm{A})$
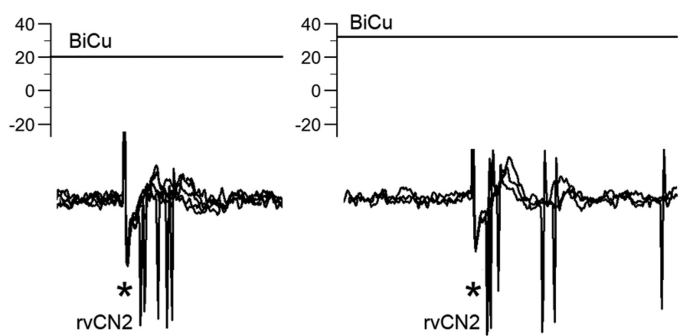

Figure 10. GABA and glycine exerted additive inhibitory effects over proprioceptive induced responses, and BiCu ejection dynamic response when tapping the muscle with an electric Von Frey probe (3), and then a $5 \mathrm{nA}$ glycine ejecting current fully abolished the response (4). Notice that the cell showed an enhanced activity upon recovery from drug withdrawal (5) at the same CN2), separated $500 \mu \mathrm{m}$ from each other, synaptically activated the cell only from rvCN2. C, Subthreshold rvCN2 stimulation in the control condition (left panel) was well suprathreshold during BiCu ejection (right two panels), indicating that GABA exerted a tonic inhibition through $\mathrm{GABA}_{\mathrm{A}}$ receptors.

tributed throughout the cuneate nucleus without any special density distribution. However, statistical significant differences in labeled cellular size were observed between the middle dorsal cutaneous and the mvCN proprioceptive regions. Cells in the cluster region were larger in average $\left(439 \pm 217.4 \mu \mathrm{m}^{2}\right.$, range: $\left.68-1759 \mu \mathrm{m}^{2}\right)$ than those more ventrally located $(387.5 \pm 229.2$ $\mu \mathrm{m}^{2}$, range: $\left.16.5-1884 \mu \mathrm{m}^{2}\right)(p<0.001$, Kruskal-Wallis). This may provide an explanation for the finding that projection cutaneous neurons had faster antidromic conduction speeds than proprioceptive projection cells, if soma size is related to axon diameter and hence also to conduction speed. Two coronal sections are shown in Figure 11 (magnified at right), one rostral and another caudal to the obex. Rostrally, particular dense labeling was also apparent at the level of two other motor-related structures, the dorsal motor nucleus of the vagus and the inferior vestibular nucleus (Fig. $11 B$, left).

These data show that $\alpha$-subunits of strychnine-sensitive glycine receptors are expressed in the cat's dorsal column nuclei, as 
A $2 \mathrm{~mm}$ caudal to the obex

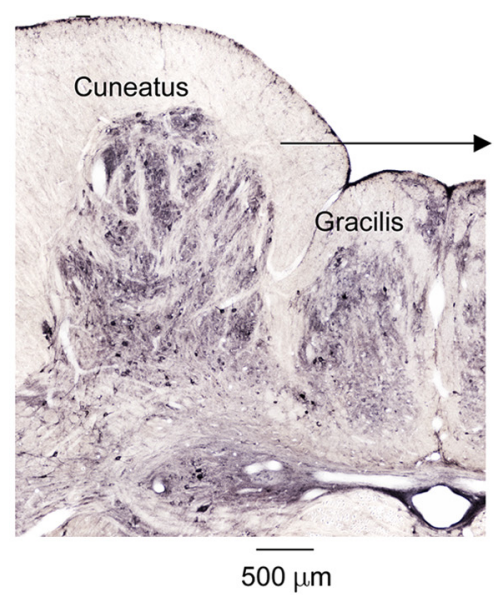

B $2 \mathrm{~mm}$ rostral to the obex
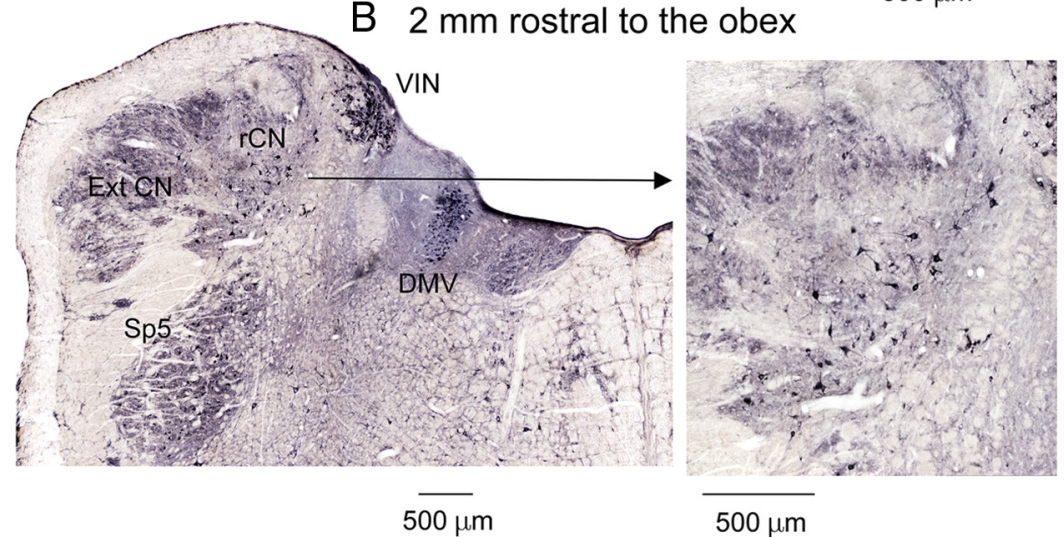

Figure 11. Cells possessing strychnine-sensitive glycine receptors were evenly distributed throughout the main cuneate nucleus. $\boldsymbol{A}, \boldsymbol{B}$, Two coronal sections (expanded at right), one $2 \mathrm{~mm}$ caudal $(\boldsymbol{A})$ and another $2 \mathrm{~mm}$ rostral $(\boldsymbol{B})$ to the obex showing dark-colored glycine receptor-immunoreactive neurons. The patchy distribution of immunoreactivity in the dorsal area corresponded to the cluster region of the cuneate nucleus (see $\boldsymbol{A}$ ). Cuneate neurons show moderate to high levels of immunoreactivity for the strychnine-sensitive glycine receptor. DMV, Dorsal motor nucleus of the vagus; ExtCN, external cuneate nucleus; rCN, rostral cuneate nucleus; Sp5, spinal trigeminal nucleus; VIN, inferior vestibular nucleus.

detected by immunohistochemical methods using the monoclonal antibody mAb4a recognizing an epitope common to all $\alpha$-subunit variants of glycine receptors (Pfeiffer et al., 1984; Schröder et al., 1991).

\section{Discussion}

This study revealed new findings concerning proprioceptive mvCN cells, which (1) had slower lemniscal antidromic conduction speeds than cutaneous cells from the cluster region; (2) responded with longer latencies to stimulation of area $3 a$ than to stimulation of motor cortex; (3) sent ipsilateral collaterals terminating in or passing through the NRGc and the MLR; (4) had activity potentiated or decreased by rvCN stimulation; and (5) had spontaneous and evoked activities suppressed by GABA and/or glycine.

The sampled neurons were most probably activated by muscle spindle primary afferents, since they faithfully followed muscular vibratory sinusoidal stimuli up to $135 \mathrm{~Hz}$. Classification of effects by SCh revealed that $50 \%$ of the neurons were probably driven by static bag2 fibers, thus suggesting a postural function for a large percentage of mvCN proprioceptive neurons.

\section{Lemniscal antidromic speeds}

mvCN fibers had slower ML-antidromic conduction velocity than cutaneous fibers originating from the cluster region (Fig.
4D). Proprioceptive afferents are faster conducting than cutaneous afferents (Fig. $4 C$ ), and the relative slowing of proprioceptive speed through the ML pathway may constitute a mechanism for matching the arrival of both classes of information to the thalamus (Andersson et al., 1966; Mallart, 1968) and the cerebral cortex. Somatosensory feedback usually relies on movements driving simultaneously, or consecutively, superficial and deep receptors to adapt centrally generated motor programs. Cutaneous and deep muscular feedback converge on vertebrate spinal central pattern generators (Hultborn and Nielsen, 2007) but ascend through parallel paths up to the cerebral primary somatosensory cortex, where convergence of both submodalities is subliminal (Zarzecki and Wiggin, 1982; Kang et al., 1985) but could reach threshold when arriving within a short time window, allowing summation of effects. In fact, cutaneous and spindle information potentiate each other in humans, in whom removal of cutaneous feedback from a moving digit decreases proprioceptive acuity (Provins, 1958), and illusion of movement induced by stretching the skin over joints (Edin and Johansson, 1995; Collins et al., 2005) increases when vibration and skin stretch are applied together (Collins and Prochazka, 1996).

\section{Cerebral cortical stimulation}

mvCN neurons were activated at longer latencies by area $3 \mathrm{a}$ than by motor cortex stimulation (Fig. 4A). Area $3 \mathrm{a}$ is part of a network involved in proprioception, postural control, and the generation of coordinated movements. It receives proprioceptive input (reviewed by Jones and Porter, 1980) and sends descending fibers that might affect mvCN neurons through different routes, including direct corticobulbar fibers and collaterals of corticospinal axons (Lamas et al., 1994; Martinez et al., 1995), and via area 2 and motor cortex (Porter, 1997). Various options are possible to explain our data: (1) Cortico-mvCN fibers from area 3 a have slower conduction speeds than those from the motor cortex; experimental evidence for this is lacking. (2) Area 3a and motor cortex affect mvCN neurons through corticobulbar and corticospinal fibers, respectively. Corticobulbar fibers are slower conducting than corticospinal fibers (Lamas et al., 1994). (3) Stimulation of area 3 a indirectly affects mvCN neurons through the motor cortex either directly (Zarzecki et al., 1978; Asanuma et al., 1982) or after a previous relay in area 2 (Porter, 1997).

\section{Collateral branching of mvCN projection neurons}

Projection mvCN cells collateralized ipsilaterally to the NRGc and the MLR. These findings were unexpected, since to our knowledge, there is no anatomical data that would predict them. However, Cesa-Bianchi and Sotgiu (1969) reported that some cuneate neurons faithfully responded to high-frequency reticular stimulation. It is unknown whether the ML collater- 
als traverse or terminate in the stimulated structures. If some of the ML collaterals to the NRGc synapse onto reticulospinal cells, then a reflex spinoreticulospinal proprioceptive pathway will be present granting a rapid motor adjustment in response to proprioceptive feedback from the moving musculature that could be indirectly modulated through mvCN collaterals to the MLR, which, in turn, projects to reticulospinal neurons (Noga et al., 2003). Another option is that the collaterals end at different loci of the reticular formation and/or more rostral structures implicated in sensorimotor integration (Hunt and O'Leary, 1952; Gaze and Gordon, 1954; Feldman et al., 1959; Chuvin, 1971; Haring and Rowinski, 1982; Björkeland and Boivie, 1984; Haring et al., 1984; Li and Mizuno, 1997; Wree et al., 2005). Although the precise target(s) of the ML collaterals are to be determined, they allow for bilateral spread of proprioceptive feedback to shape and adapt the forelimb motor patterns.

\section{mvCN and rvCN neurons are functionally interrelated}

Proprioceptive neurons were apparently driven from a single muscle, supporting previous work (Rosén, 1969a,b; Rosén and Sjölund, 1973; Hummelsheim and Wiesendanger, 1985; Mackie et al., 1998). mvCN projection cells with receptive fields in a given muscle were activated by rvCN stimulating sites receiving excitatory input not only from that muscle but also from sites with input from its agonists and/or antagonists. This would imply that (1) the same proprioceptive input reaches rvCN and mvCN neurons, probably through fiber collateralization and/or via afferents from different proprioceptors, and (2) the rvCN-mvCN network is functionally related to joints rather than to single muscles.

Processing information from whole articulations would be an economic way to modulate the activity of mvCN projection neurons. Thus, during single-joint movement, mvCN and rvCN neurons receiving input from stretched spindles increase activity, while neurons receiving input from shortened spindles are disfacilitated. At the same time, the activated muscle proprioceptors increase the activity of inhibitory interneurons at the $\mathrm{rvCN}$ and/or mvCN, inhibiting mvCN projection neurons receiving deep input from other articulations. Information would thus be transmitted signaling muscular feedback from a particular forelimb articulation.

The population of recorded neurons had dynamic as well as static properties, very much like the spindle afferents driving them (Mackie et al., 1998). Using passive movement to drive cells in paralyzed (de-efferented) animals, as in the present work, is akin to muscular proprioceptive feedback during active movement performance. Since the mvCN neurons, as a population, exhibited tonic and phasic discharges related to joint angle and to the dynamic phase of stretching, they convey static and dynamic information contralaterally as well as ipsilaterally through CL collaterals.

Whereas the decrease of lemniscal activity before active movement can be attributed to central feedback, probably of cerebral cortical origin (Soso and Fetz, 1980), its decrease during movement performance (Ghez and Lenzi, 1971; Coulter, 1974; Chapman et al., 1988) probably depends on peripheral proprioceptive feedback potentiated through the rvCN and the cerebral cortex. The mvCN would shape feedback proprioceptive transmission, producing an overall filtering by potentiating proprioceptive information from a moving joint while filtering information from other joints. This model (Fig. 12) implies that the cuneate will not discriminate information from agonists and antagonists of an articulation but between different articulations, and that cuneate

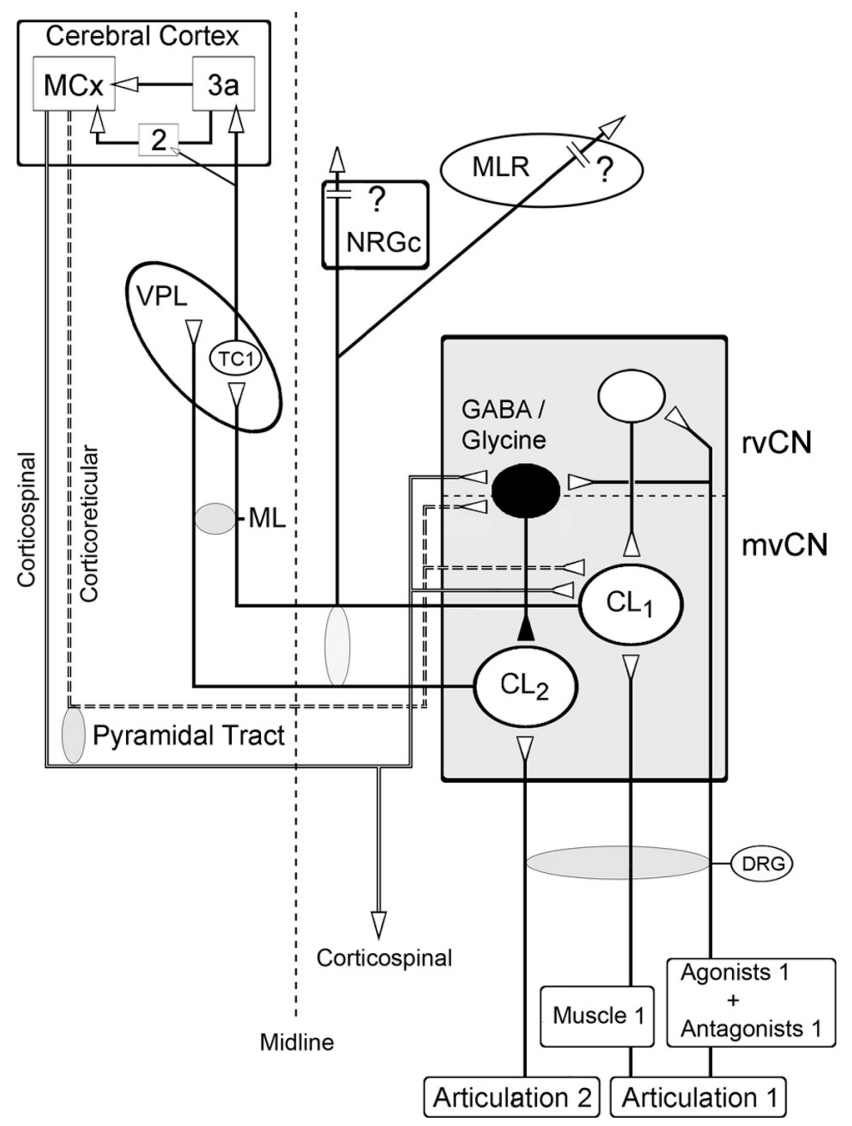

Figure 12. Proposed intracuneate circuitry underlying processing of ascending proprioceptive information. The activity of a population of proprioceptive cuneolemniscal cells $\left(\mathrm{CL}_{1}\right)$ receiving muscular input from a moving joint is potentiated through excitatory interneurons in the rostral cuneate that also receive proprioceptive input from that same joint. These same signals from the moving joint inhibit other cuneolemniscal cells $\left(\mathrm{CL}_{2}\right)$, through $\mathrm{GABAergic}$ and/or glycinergic interneurons, receiving proprioceptive input from other joints. The proprioceptive cuneolemniscal axons collateralize to or through the ipsilateral NRGc and MLR on their way to the contralateral ventroposterior thalamic (VPL) nucleus, thus spreading bilaterally. The thalamocortical fibers from the VPL reach area $3 a$ and some also area 2, which, in turn, relay information to the motor cortex (MCX), which sends descending fibers to the mvCN and rvCN (not shown) through the pyramidal tract. This cortical feedback can be exerted through direct corticoreticular axons as well as via collaterals of corticospinal fibers, probably potentiating ascending information from the moving joint while inhibiting ascending cuneolemniscal output from other joints.

cells sensitive to proprioceptive input from distinct articulations will be activated sequentially and not concurrently, which also would diminish ambiguous signals from muscles crossing more than one joint. The rvCN-mvCN network would thus play a functional role in interjoint coordination using functional modules to map articulation features of forelimb movement updating the internal representation of the forelimbs and recruiting cerebral cortical-specific motor networks in a precise spatial-temporal manner as described in primates performing reaching movements (Murphy et al., 1985).

\section{GABA and glycine constrained mvCN responses to a single articulation}

Whereas the interneurons within the medial cuneate nucleus appear to be inhibitory (Andersen et al., 1964b; Barbaresi et al., 1986; Berkley et al., 1986; Rustioni and Weinberg, 1989; Heino and Westman, 1991), this work demonstrated that excitatory interneurons are present at the rvCN. The suppression of mvCN activity by GABA and glycine applied together was more effective 
than that produced by GABA or glycine independently iontophoresed, suggesting that the strength of inhibition is increased when both inhibitory systems are active. rvCN-evoked inhibition on mvCN neurons was only produced when stimulating at sites with fields at different articulations than the one activating the mvCN cells, suggesting that spatial inhibition constrained the responses of these cells to a single articulation. GABA and glycine probably act on different receptors at the same neuron, since their effects were reversed by $\mathrm{BiCu}$ and strychnine, respectively. Whether in physiological conditions both neurotransmitters are coreleased by the same or different terminals is unknown, but cotransmission is common in the CNS (Burnstock, 2004); GABA and glycine colocalize in the rat's dorsal column nuclei (Popratiloff et al., 1996), and their functional corelease has been reported in other regions of the brainstem (O'Brien and Berger, 1999; Russier et al., 2002; Awatramani et al., 2005; Lu et al., 2008). Corelease and/or simultaneity of action on postsynaptic receptors will increase the efficiency of synaptic transmission.

Strychnine and BiCu increased excitability indicating that glycine and GABA tonically inhibit mvCN activity probably filtering weak, irrelevant activity. Finally, strychnine-sensitive glycine receptors were homogeneously distributed throughout the main cuneate nucleus, but their functional role on ascending transmission appears to vary in different loci, since whereas in the cluster region they disinhibit ascending cutaneous output through GABAergic interneurons (Aguilar et al., 2003), in the mvCN they play a pure inhibitory role.

\section{Conclusion}

The present findings provide novel insights into the function of the $\mathrm{mvCN}$ in processing feedback proprioceptive information, demonstrating that mvCN projection neurons receiving inputs from muscles of a single articulation are potentiated through rostral cuneate excitatory interneurons receiving muscular inputs from that same articulation (Fig. 12). At the same time, these proprioceptive inputs activate GABA and/or glycine interneurons at the rostral and/or mvCN, inhibiting projection mvCN cells receiving proprioceptive input from other articulations. The relevant ascending proprioceptive information signaling the state of an articulation reaches the contralateral cortical area $3 \mathrm{a}$, which, through the motor cortex, potentiates the most activated mvCN projection cells. The cortex may thus select, at the prethalamic level and through corticoreticular and collaterals of corticospinal fibers, the relevant proprioceptive information it processes. Furthermore, the ascending selected proprioceptive signals are also transmitted ipsilaterally through medial lemniscal collaterals whose final targets are currently unknown (Fig. 12).

\section{References}

Aguilar J, Soto C, Rivadulla C, Canedo A (2002) The lemniscal-cuneate recurrent excitation is suppressed by strychnine and enhanced by GABAa antagonists in the anaesthetized cat. Eur J Neurosci 16:1697-1704.

Aguilar J, Rivadulla C, Soto C, Canedo A (2003) New corticocuneate cellular mechanisms underlying the modulation of cutaneous ascending transmission in anesthetized cats. J Neurophysiol 89:3328-3339.

Andersen P, Eccles JC, Schmidt RF, Yokota T (1964a) Slow potential waves produced in the cuneate nucleus by cutaneous volleys and by cortical stimulation. J Neurophysiol 27:78-91.

Andersen P, Eccles JC, Oshima T, Schmidt RF (1964b) Mechanisms of synaptic transmission in the cuneate nucleus. J Neurophysiol 27:1096-1116.

Andersson SA, Landgren S, Wolsk D (1966) The thalamic relay and cortical projection of group I muscle afferents from the forelimb of the cat. J Physiol 183:576-591.

Armstrong DM (1988) The supraspinal control of mammalian locomotion. J Physiol 405:1-37.
Asanuma H, Waters RS, Yumiya H (1982) Physiological properties of neurons projecting from area 3 a to area $4 \gamma$ of feline cerebral cortex. J Neurophysiol 48:1048-1057.

Awatramani GB, Turecek R, Trussell LO (2005) Staggered development of GABAergic and glycinergic transmission in the MNTB. J Neurophysiol 93:819-828.

Barbaresi P, Spreafico R, Frassoni C, Rustioni A (1986) GABAergic neurons are present in the dorsal column nuclei but not in the ventroposterior complex of rats. Brain Res 382:305-326.

Becker CM (1992) Convulsants acting at the inhibitory glycine receptor. In: Handbook of experimental pharmacology, Vol 102 (Herken H, Hucho F, eds.), pp 539-575. Berlin: Springer.

Berkley KJ, Budell RJ, Blomqvist A, Bull M (1986) Output systems of the dorsal column nuclei in the cat. Brain Res 11:199-225.

Bianconi R, van der Meulen JP (1963) The response to vibration of the end organs of mammalian muscle spindles. J Neurophysiol 26:177-190.

Björkeland M, Boivie J (1984) An anatomical study of the projections from the dorsal column nuclei to the midbrain in cat. Anat Embryol 170:29-43.

Blum P, Bromberg MB, Whitehorn D (1975) Population analysis of single units in the cuneate nucleus of the cat. Exp Neurol 48:57-78.

Bormann J, Hamill OP, Sakmann B (1987) Mechanism of anion permeation through channels gated by glycine and gamma-aminobutyric acid in mouse cultured spinal neurones. J Physiol 385:243-286.

Brown MC, Engberg I, Matthews PBC (1967) The relative sensitivity to vibration of muscle receptors of the cat. J Physiol 192:773-800.

Burgess PR, Clark FJ (1969) Characteristics of knee joint receptors in the cat. J Physiol 203:317-335.

Burnstock G (2004) Cotransmission. Curr Opin Pharmacol 4:47-52.

Bystrzycka E, Nail BS, Rowe M (1977) Inhibition of cuneate neurones: its afferent source and influence on dynamically sensitive "tactile" neurones. J Physiol 268:251-270.

Cerminara NL, Makarabhirom K, Rawson JA (2003) Somatosensory properties of cuneocerebellar neurones in the main cuneate nucleus of the rat. Cerebellum 2:131-145.

Canedo A (1997) Primary motor cortex influences on the descending and ascending systems. Prog Neurobiol 51:287-335.

Canedo A, Mariño J, Aguilar J (2000) Lemniscal recurrent and transcortical influences on cuneate neurons. Neuroscience 97:317-334.

Carmody J, Rowe M (1974) Inhibition within the trigeminal nucleus induced by afferent inputs and its influence on stimulus coding by mechanosensitive neurones. J Physiol 243:195-210.

Cesa-Bianchi MG, Sotgiu ML (1969) Control by brain stem reticular formation of sensory transmission in Burdach nucleus. Analysis of single units. Brain Res 13:129-139.

Chapman CE, Jiang W, Lamarre Y (1988) Modulation of lemniscal input during conditioned arm movements in the monkey. Exp Brain Res $72: 316-334$.

Cheek MD, Rustioni A, Trevino DL (1975) Dorsal column nuclei projections to the cerebellar cortex in cats as revealed by the use of the retrograde transport of horseradish peroxidase. J Comp Neurol 164:31-46.

Chuvin BT (1971) Pathways of activation of neurons of the mesencephalic reticular formation. Bull Exp Biol Med 72:1110-1112.

Clark FJ, Burgess PR (1975) Slowly adapting receptors in cat knee joint: can they signal joint angle? J Neurophysiol 38:1448-1463.

Collins DF, Prochazka A (1996) Movement illusions evoked by ensemble cutaneous input from the dorsum of the human hand. J Physiol 496:857-871.

Collins DF, Refshauge KM, Todd G, Gandevia SC (2005) Cutaneous receptors contribute to kinesthesia at the index finger, elbow, and knee. J Neurophysiol 94:1699-1706.

Cooke JD, Larson B, Oscarsson O, Sjölund B (1971a) Origin and termination of cuneocerebellar tract. Exp Brain Res 13:339-358.

Cooke JD, Larson B, Oscarsson O, Sjölund B (1971b) Organization of afferent connections to cuneocerebellar tract. Exp Brain Res 13:359-377.

Coulter JD (1974) Sensory transmission through lemniscal pathway during voluntary movement in the cat. J Neurophysiol 37:831-845.

Darstein M, Landwehrmeyer GB, Kling C, Becker C-M, Feuerstein TJ (2000) Strychnine-sensitive glycine receptors in rat caudatoputamen are expressed by cholinergic interneurons. Neuroscience 96:33-39.

Dostrovsky JO, Millar J, Wall PD (1976) The immediate shift of afferent drive of dorsal column nucleus cells following deafferentation: a compar- 
ison of acute and chronic deafferentation in gracile nucleus and spinal cord. Exp Neurol 52:480-495.

Douglas PR, Ferrington DG, Rowe M (1978) Coding of information about tactile stimuli by neurones of the cuneate nucleus. J Physiol 285:493-513.

Durbaba R, Taylor A, Ellaway PH, Rawlinson S (2006) Classification of longissimus lumborum muscle spindle afferents in the anaesthetized cat. J Physiol 571:489-498.

Dykes RW, Rasmusson DD, Sretavan D, Rehman NB (1982) Submodality segregation and receptive-field sequences in cuneate, gracile, and external cuneate nuclei of the cat. J Neurophysiol 47:389-416.

Edin BB, Johansson N (1995) Skin strain patterns provide kinaesthetic information to the human central nervous system. J Physiol 487:243-251.

Edin BB, Vallbo AB (1990) Dynamic response of human muscle spindle afferents to stretch. J Neurophysiol 63:1297-1306.

Edwards SB (1972) The ascending and descending projections of the red nucleus in the cat: an experimental study using an autoradiographic tracing method. Brain Res 48:45-63.

Ellis LC Jr, Rustioni A (1981) A correlative HRP, Golgi and EM study of the intrinsic organization of the feline dorsal column nuclei. J Comp Neurol 197:341-367.

Feldman S, Van der Heide CS, Porter RW (1959) Evoked potentials in the hypothalamus. Am J Physiol 196:1163-1167.

Gaze RM, Gordon G (1954) The representation of cutaneous sense in the thalamus of the cat and monkey. Q J Exp Physiol Cogn Med Sci 39:279-304.

Ghez C, Lenzi GL (1971) Modulation of sensory transmission in cat lemniscal system during voluntary movements. Pflugers Arch 323:273-278.

Ghez C, Pisa M (1972) Inhibition of afferent transmission in cuneate nucleus during voluntary movement in the cat. Brain Res 40:145-155.

Golovchinsky V (1980) Patterns of responses of neurons in cuneate nucleus to controlled mechanical stimulation of cutaneous velocity receptors in the cat. J Neurophysiol 43:1673-1699.

Gordon G, Jukes MGM (1964) Dual organization of the exteroceptive components of the cat's gracile nucleus. J Physiol 173:263-290.

Grill SE, Hallett M (1995) Velocity sensitivity of human muscle spindle afferents and slowly adapting type II cutaneous mechanoreceptors. J Physiol 489:593-602.

Hand PJ, Van Winkle T (1977) The efferent connections of the feline nucleus cuneatus. J Comp Neurol 171:83-109.

Haring JH, Rowinski MJ (1982) A horseradish peroxidase study of projections from the main and external cuneate nuclei to the cerebellum of the North American raccoon. J Comp Neurol 211:363-376.

Haring JH, Rowinski MJ, Pubols BH Jr (1984) Electrophysiology of raccoon cuneocerebellar neurons. Somatosens Res 1:247-264.

Harvey RJ, Matthews PBC (1961) The response of de-efferented muscle spindle endings in the cat's soleus to slow extension of the muscle. J Physiol 157:370-392.

Heino R, Westman J (1991) Quantitative analysis of the feline dorsal column nuclei and their GABAergic and non-GABAergic neurons. Anat Embryol 184:181-193.

Hultborn H, Nielsen JB (2007) Spinal control of locomotion-from cat to man. Acta Physiol (Oxf) 189:111-121.

Hummelsheim H, Wiesendanger M (1985) Neuronal responses of medullary rely cells to controlled stretches of forearm muscles in the monkey. Neuroscience 16:989-996.

Hummelsheim H, Wiesendanger R, Wiesendanger M, Bianchetti M (1985) The projection of low-threshold muscle afferents of the forelimb to the main and external cuneate nuclei of the monkey. Neuroscience 16:979-987.

Hunt WE, O'Leary JL (1952) Form of thalamic response evoked by peripheral nerve stimulation. J Comp Neurol 97:491-514.

Itoh K, Kamiya H, Mitani A, Yasui Y, Takada M, Mizuno N (1987) Direct projections from the dorsal column nuclei and the spinal trigeminal nuclei to the cochlear nuclei in the cat. Brain Res 400:145-150.

Jones EG, Porter R (1980) What is area 3a? Brain Res Rev 2:1-43.

Jordan LM (1998) Initiation of locomotion in mammals. Ann NY Acad Sci 860:83-93.

Kang R, Herman D, MacGillis M, Zarzecki P (1985) Convergence of sensory inputs in somatosensory cortex: interactions from separate afferent sources. Exp Brain Res 57:271-278.

Kelly JS, Renaud LP (1973) On the pharmacology of ascending, descending and recurrent postsynaptic inhibition of the cuneo-thalamic relay cells in the cat. Br J Pharmacol 48:396-408.

Kruger L, Siminoff R, Witkovsky P (1961) Single neuron analysis of dorsal column nuclei and spinal nucleus of trigeminal in cat. J Neurophysiol 24:333-349.

Kuhn RA (1949) Topographical pattern of cutaneous sensibility in the dorsal column nuclei of the cat. Trans Am Neurol Assoc 74:227-230.

Kuypers HGJM, Tuerk JD (1964) The distribution of the cortical fibers within the nuclei cuneatus and gracilis in the cat. J Anat 98:143-162.

Lamas JA, Martinez L, Canedo A (1994) Pericruciate fibres to the red nucleus and to the medial bulbar reticular formation. Neuroscience 62:115-124.

Leiras R, Velo P, Martín-Cora F, Canedo A (2009) Rostral cuneate nucleus neurons modulate the activity of proprioceptive cuneolemniscal cells of the middle cuneate in anesthetized cats. Soc Neurosci Abstr 35:562.7.

Li H, Mizuno N (1997) Collateral projections from single neurons in the dorsal column nuclei to the inferior colliculus and the ventrobasal thalamus: a retrograde double-labeling study in the rat. Neurosci Lett 225:21-24.

Lu T, Rubio ME, Trussell LO (2008) Glycinergic transmission shaped by the corelease of GABA in a mammalian auditory synapse. Neuron 57:524-535.

Lundberg A, Winsbury G (1960) Selective adequate activation of large afferents from muscle spindles and Golgi tendon organs. Acta Physiol Scand 49:155-164.

Mackie PD, Morley JW, Zhang HQ, Murray GM, Rowe MJ (1998) Signalling of static and dynamic features of muscle spindle input by cuneate neurones in the cat. J Physiol 510:923-939.

Mackie PD, Morley JW, Rowe MJ (1999) Signalling of static and dynamic features of muscle spindle input by external cuneate neurones in the cat. J Physiol 519:559-569.

Mallart A (1968) Thalamic projection of muscle nerve afferents in the cat. J Physiol 194:337-353.

Martinez L, Lamas JA, Canedo A (1995) Pyramidal tract and corticospinal neurons with branching axons to the dorsal column nuclei of the cat. Neuroscience 68:195-206.

Matthews BHC (1933) Nerve endings in mammalian muscle. J Physiol 78:1-53.

Matthews PBC (1981) Evolving views of the internal operation and functional role of the muscle spindle. J Physiol 320:1-30.

Matthews PBC, Stein RB (1969) The sensitivity of muscle spindle afferents to small sinusoidal changes of length. J Physiol 200:723-743.

McCloskey DI (1978) Kinesthetic sensibility. Physiol Rev 58:763-820.

McCurdy ML, Houk JC, Gibson AR (1998) Organization of ascending pathways to the forelimb area of the dorsal accessory olive in the cat. J Comp Neurol 392:115-133.

Millar J, Basbaum AI (1975) Topography of the projection of the body surface of the cat to cuneate and gracile nuclei. Exp Neurol 49:281-290.

Millar J, Basbaum AI, Wall PD (1976) Restructuring of the somatotopic map and appearance of abnormal neuronal activity in the gracile nucleus after partial deafferentation. Exp Neurol 50:658-672.

Murphy JT, Wong YC, Kwan HC (1985) Sequential activation of primate motor cortex during unrestrained forelimb movement. J Neurophysiol 53:435-445.

Noga BR, Kriellaars DJ, Brownstone RM, Jordan LM (2003) Mechanism for activation of locomotor centers in the spinal cord by stimulation of the mesencephalic locomotor region. J Neurophysiol 90:1464-1478.

Nyberg G, Blomqvist A (1982) The termination of forelimb nerves in the feline cuneate nucleus demonstrated by the transganglionic transport method. Brain Res 248:209-222.

O’Brien JA, Berger AJ (1999) Cotransmission of GABA and glycine to brain stem motoneurons. J Neurophysiol 82:1638-1641.

Panetsos F, Nuñez A, Avendaño C (1995) Local anesthesia induces immediate receptive field changes in nucleus gracilis and cortex. Neuroreport 7:150-152.

Perl ER, Whitlock DG, Gentry JR (1962) Cutaneous projection to second order neurons of the dorsal column system. J Neurophysiol 25:337-358.

Pettit MJ, Schwark HD (1993) Receptive field reorganization in dorsal column nuclei during temporary denervation. Science 262:2054-2056.

Pfeiffer F, Simler R, Grenningloh G, Betz H (1984) Monoclonal antibodies and peptide mapping reveal structural similarities between the subunits 
of the glycine receptor of rat spinal cord. Proc Natl Acad Sci U S A 81:7224-7227.

Popratiloff A, Valtschanoff JG, Rustioni A, Weinberg RJ (1996) Colocalization of GABA and glycine in the rat dorsal column nuclei. Brain Res 706:308-312.

Porter LL (1997) Morphological characterization of a cortico-cortical relay in the cat sensorimotor cortex. Cereb Cortex 7:100-109.

Provins KA (1958) The effect of peripheral nerve block on the appreciation and execution of finger movements. J Physiol 143:55-67.

Pubols BH Jr, Welker WI, Johnson JI Jr (1965) Somatic sensory representation of forelimb in dorsal root fibers of raccoon, coatimundi, and cat. J Neurophysiol 28:312-341.

Pubols BH Jr, Haring JH, Rowinski MJ (1989) Patterns of resting discharge in neurons of the raccoon main cuneate nucleus. J Neurophysiol 61:1131-1141.

Roberts MHT, Gould T (1993) Iontophoresis in the mammalian central nervous system. In: Electrophysiology: a practical approach (Wallis DI, ed), pp 239-263. New York: Oxford UP.

Rosén I (1967) Functional organization of group I activated neurons in the cuneate nucleus of the cat. Brain Res 6:770-772.

Rosén I (1969a) Afferent connections to group I activated cells in the main cuneate nucleus of the cat. J Physiol 205:209-236.

Rosén I (1969b) Excitation of group I activated thalamocortical relay neurones in the cat. J Physiol 205:237-255.

Rosén I, Sjölund B (1973) Organization of group I activated cells in the main and external cuneate nuclei of the cat: identification of muscle receptors. Exp Brain Res 16:221-237.

Rowinski MJ, Haring JH, Pubols BH Jr (1985) Response properties of raccoon cuneothalamic neurons. Somatosens Res 2:263-280.

Russier M, Kopysova IL, Ankri N, Ferrand N, Debanne D (2002) GABA and glycine co-release optimizes functional inhibition in rat brainstem motoneurons in vitro. J Physiol 541:123-137.

Rustioni M, Weinberg RJ (1989) The somatosensory system. In: Handbook of chemical neuroanatomy: integrated systems of the CNS (Björklund A, Hökfelt T, Swanson LW, eds), Vol 7, Pt II, Chap III, pp 219-230. Amsterdam: Elsevier.

Schröder S, Hoch W, Becker C-M, Grenningloh G, Betz H (1991) Mapping of antigenic epitopes on the alpha 1 subunit of the inhibitory glycine receptor. Biochemistry 30:42-47.

Soso MJ, Fetz EE (1980) Responses of identified cells in postcentral cortex of awake monkeys during comparable active and passive joint movements. J Neurophysiol 43:1090-1110.

Soto C, Aguilar J, Martín-Cora F, Rivadulla C, Canedo A (2004) Intracuneate mechanisms underlying afferent cutaneous processing in anaesthetized cats. Eur J Neurosci 19:3006-3016.
Soto C, Martín-Cora F, Leiras R, Velo P, Canedo A (2006) GABA receptormediated modulation of cutaneous input at the cuneate nucleus in anaesthetized cats. Neuroscience 137:1015-1030.

Stuart DG, Mosher CG, Gerlach RL, Reinking RM (1970) Selective activation of Ia afferents by transient muscle stretch. Exp Brain Res 10:477-487.

Takakusaki K, Habaguchi T, Ohtinata-Sugimoto J, Saitoh K, Sakamoto T (2003) Basal ganglia efferents to the brainstem centers controlling postural muscle tone and locomotion: a new concept for understanding motor disorders in basal ganglia dysfunction. Neuroscience 119:293-308.

Taylor A, Rodgers JF, Fowle AJ, Durbaba R (1992) The effect of succinylcholine on cat gastrocnemius muscle spindle afferents of different types. J Physiol 456:629-644.

Uddenberg N (1966) Studies on modality segregation and second-order neurons in the dorsal funiculus. Experientia 22:441-442.

Weinberg RJ, Rustioni A (1987) Cuneocochlear pathway in the rat. Neuroscience 20:209-219.

Whelan PJ (1996) Control of locomotion in the decerebrate cat. Prog Neurobiol 49:481-515.

Whitsel BL, Petrucelli LM, Sapiro G (1969) Modality representation in the lumbar and cervical fasciculus gracilis of squirrel monkeys. Brain Res 15:67-78

Wiberg M, Blomqvist A (1984) The projection to the mesencephalon from the dorsal column nuclei. An anatomical study in the cat. Brain Res 311:225-244.

Winn P (2008) Experimental studies of pedunculopontine functions: are they motor, sensory or integrative? Parkinsonism Relat Disord 14:S194S198.

Winter DL (1965) N. Gracilis of cat. Functional organization and corticofugal effects. J Neurophysiol 28:48-70.

Wree A, Itzev DE, Schmitt O, Usunoff KG (2005) Neurons in the dorsal column nuclei of the rat emit a moderate projection to the ipsilateral ventrobasal thalamus. Anat Embryol 210:155-162.

Wright DD, Ryugo DK (1996) Mossy fiber projections from the cuneate nucleus to the cochlear nucleus in the rat. J Comp Neurol 365:159-172.

Yamamoto S, Sugihara S, Kuru M (1956) Microelectrode studies on sensory afferents in the posterior funiculus of cat. Jpn J Physiol 6:68-85.

Young AB, Snyder SH (1973) Strychnine binding associated with glycine receptors of the central nervous system. Proc Natl Acad Sci U S A 70:2832-2836.

Zarzecki P, Wiggin DM (1982) Convergence of sensory inputs upon projection neurons of somatosensory cortex. Exp Brain Res 48:28-42.

Zarzecki P, Shinoda Y, Asanuma H (1978) Projection from area 3a to the motor cortex by neurons activated from group I muscle afferents. Exp Brain Res 33:269-282. 